\title{
Study of using cutting chip color to the tool wear prediction
}

\author{
Shao-Hsien Chen ${ }^{1} \cdot$ Zhi-Rong Luo $^{2}$
}

Received: 5 February 2020 / Accepted: 22 April 2020 / Published online: 9 July 2020

(C) The Author(s) 2020

\begin{abstract}
In this study, the correlation between chip surface chromaticity and wear of cutting tools is established through experiments, and a system for judging and predicting tool wear by observing chip color is proposed. At present, the life prediction of cutting tools is indirectly measured and predicted by using vibration and current. In this study, chip color change is used to predict tool wear, and back-propagation Artificial Neural Networks (ANN) is used to predict and verify. The average error percentage between the predicted value and the actual value of tool wear is only $1.73 \%$ and $1.66 \%$, respectively, which was confirmed by cutting test and verification experiments. This study uses Taylor's tool life model and chip color to analyze, and after repeated tests and experimental analysis, the average error of repeatability is $4.5 \%$. In the verification of stainless steel cutting hard-cutting materials, the equipment accuracy is between 0.5 and 3.0 color difference values of grade 2 to 3 . Therefore, the measurement and model establishment of the system can accurately and quickly predict tool wear. In prediction experiment and analysis, the back neural network is used for test, the maximum error ranges are $0.0012 \mathrm{~mm}$ and $0.0097 \mathrm{~mm}$, the mean error percentages are only $1.73 \%$ and $1.66 \%$.
\end{abstract}

Keywords Cutting tool wear $\cdot$ Chip surface $\cdot$ Color correction

\section{Introduction}

In the aerospace, national defense, die making, and machinery industry, the determination of tool wear directly affects cost and competitiveness. Therefore, it has been of a pivotal position. At present, the main way of research is to use sensor to collect machine signals and analyze it with the processing parameters $[1,2]$. Although this can produce a fairly high degree of accuracy, the measurement of the sensor needs to pass the force flow line. In terms of judging parameters, this is a more indirect way, so it is difficult to fully reflect the actual situation of cutting, let alone the problem of repeated signal values. When we use the same sensor to measure different manufacturing materials or differently designed tools and machines, the value of the signal will be completely different

Shao-Hsien Chen

e6036@ncut.edu.tw

1 The Graduate Institute of Precision Manufacturing, National Chin-Yi University of Technology, No.57, Sec. 2, Zhongshan Rd., Taiping Dist., Taichung 41170, Taiwan

2 Department of Mechanical Engineering, National Chin-Yi University of Technology, No.57, Sec. 2, Zhongshan Rd., Taiping Dist., Taichung 41170, Taiwan because of the force flow line transmission. In this way, each time a wear determination model is established, only one type of tool for one machine can be determine. When one needs a lot of modeling to deal with various tools and machines, this will lead to an increase in time and cost. How to improve the problem of the repetitiveness of sensor measurement signals or to find new alternatives is the current important topic for research [3-5].

Based on this problem, this study proposes to use the method of observing the surface color of metal chip [6] to predict tool wear value. Since the chip tool will directly contact the tool during cutting, this method is more reflective of the current situation of cutting than the method of measuring signals by using processing parameters and sensors. In the study, researcher(s) used an industrial camera to capture the surface color of the chip and obtained color information CIExy chromaticity coordinates through software application. Then, based on the three parameters of tool wear values, cutting time, and chip color, a set of wear determination model can be established. Finally, in the test and verification experiments, one can confirm that the prediction model of this study is accurate enough to complete the study of the impact of chip features on the tool life $[7,8]$.

Korkut et al. [9] published the findings regarding the study of the relationship between cutting parameters and chip surface 


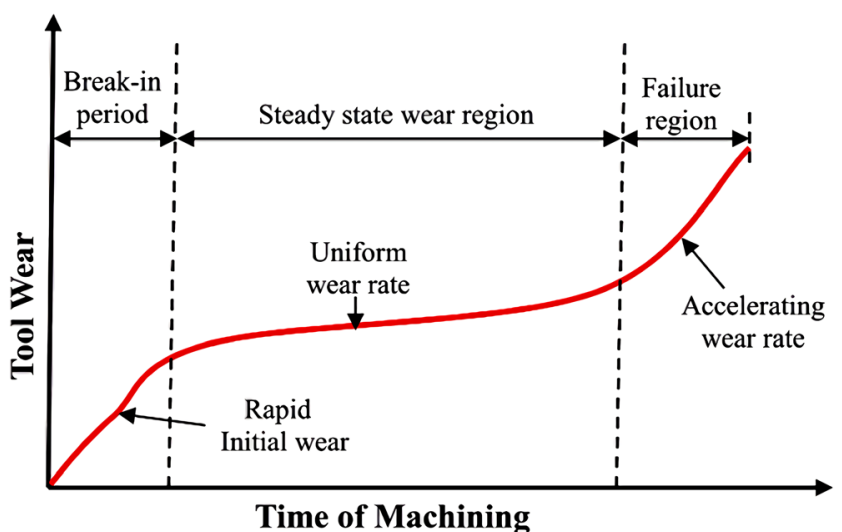

Fig. 1 Diagram of flank wear periods

temperatures during the AISI 1117 turning steel process. The three parameters of the chip surface temperature change for comparison in terms of different machining velocities, amount of feeds per revolution, and the depth of cutting. The experimental results show that the increase in machining velocity, feed rate, or depth of cutting will raise chip temperatures. The machining velocity and depth of cutting are significant factors causing the change in temperatures of the chip surface.

Tekiner and Yesilyurt [10] published the parameter study of cutting stainless steel AISI304 and found that under the condition of high machining velocity and low feed per revolution, the curl radius of the metal chip will increase, with the chip thickness becoming thinner. Thinner chip can reduce the power consumption of the processing machine, allowing the machined parts to have superior surface roughness. In addition, the study also found that the chip flow rate is slow at low machining velocity and high feed per revolution and the high temperature generated by the cutting will make the chip appear yellow.

Das et al. [11] have published a study on cost estimation by use of the parameters of surface roughness, tool wear, and chip type of cutting AISI 4340 steel. ANOVA analysis shows that the dominant parameter affecting surface roughness is mainly feed per revolution, followed by machining velocity. The surface roughness increases as the feed per revolution accelerates; the machining velocity is inversely proportional. The influence laid by the tool wear is the machining velocity, the feed per revolution, and the depth of chip. As for the chip type, the machining velocity will mainly produce three kinds of chip types, ranging

Table 1 The 2316ISO-B MOD composition of stainless steel element (\%) $[14]$

\begin{tabular}{llllllll}
\hline $\mathrm{C}$ & $\mathrm{Si}$ & $\mathrm{Mn}$ & $\mathrm{P}$ & $\mathrm{S}$ & $\mathrm{Cr}$ & $\mathrm{Ni}$ & $\mathrm{Mo}$ \\
\hline 0.28 & 0.3 & 0.95 & 0.03 & 0.003 & 14.2 & $\sim 0.5$ & 1.1 \\
\hline
\end{tabular}

Table 2 The 2316ISO-B MOD physical properties of stainless steel [22]

\begin{tabular}{clll}
\hline Thermal expansion & $20 \sim 100{ }^{\circ} \mathrm{C}$ & $20 \sim 250{ }^{\circ} \mathrm{C}$ & $20 \sim 500{ }^{\circ} \mathrm{C}$ \\
coefficient $\left(10^{-6} / \mathrm{K}\right)$ & 10 & 12 & 13.2 \\
Thermal conductivity & $20{ }^{\circ} \mathrm{C}$ & $250{ }^{\circ} \mathrm{C}$ & $500{ }^{\circ} \mathrm{C}$ \\
coefficient $(\mathrm{W} / \mathrm{mK})$ & 23 & 24 & 25 \\
Young's coefficient $(\mathrm{kN} / \mathrm{mm} 2)$ & $20{ }^{\circ} \mathrm{C}$ & $250{ }^{\circ} \mathrm{C}$ & $500{ }^{\circ} \mathrm{C}$ \\
& 215 & 203 & 180 \\
\hline
\end{tabular}

from slow to fast: spiral curl, long strip shape, and short strip shape, with the thickness becoming gradually thinner with the increase in the machining speed and the decrease in feeds per revolution.

As Zhang and Guo [12] published the milling of AISHH13 tool steel, their research report addressed how the chip type, phase change, and oxidation reaction cause relevant effect. Their experiment found that the machining velocity and feed per tooth are the key factors affecting the chip type, with the maximum influence of per blade feed. In the X-ray photoelectron spectroscopy of the chip oxide layer for two different cutting conditions. The composition of the oxide layer element changes from $\mathrm{Fe}_{2} \mathrm{O}_{3}$ to $\mathrm{Fe}_{3} \mathrm{O}_{4}$ as the cutting temperature rises, in turn causing the chip to gradually become dark blue.

In the report published by Ning et al. [13], the high-speed end milling was performed by using the die steel AISI H13, with the cutting temperature was determining by analyzing the chip color. It use a ball cutter for high-speed end milling at 10,000 $30,000 \mathrm{rpm}$. the relationship between the color and the temperature of the chip at different spindle speeds and depths of cutting. The result shows that as the spindle speed and depth of cut increase, all cutting temperatures consistently show an upward inclination.

The chip color is rarely used in literature to judge tool life and machining status, but many engineers will use chip color to judge the cutting status; this study applies engineer's experience to a digitization. Although much research has been

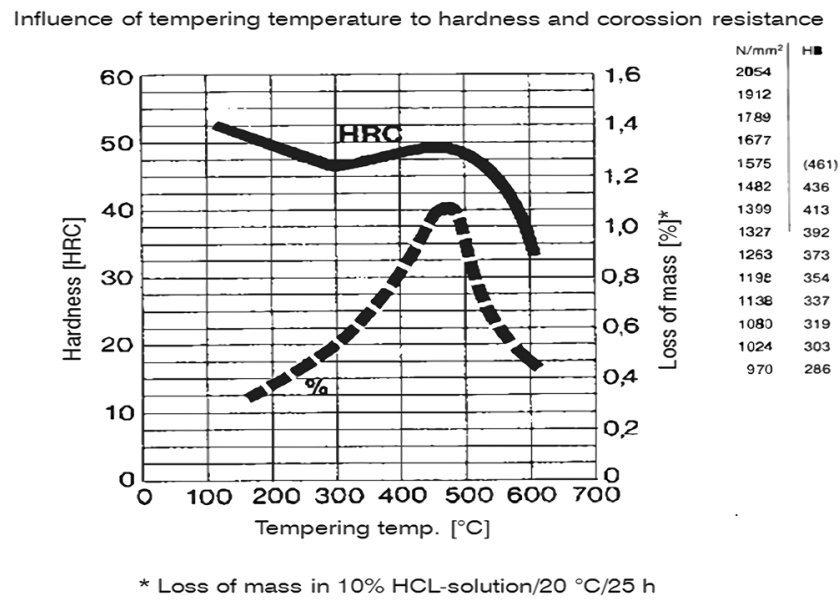

Fig. 2 The 2316ISO-B MOD effect of tempering temperature of stainless steel on hardness and corrosion resistance [22] 


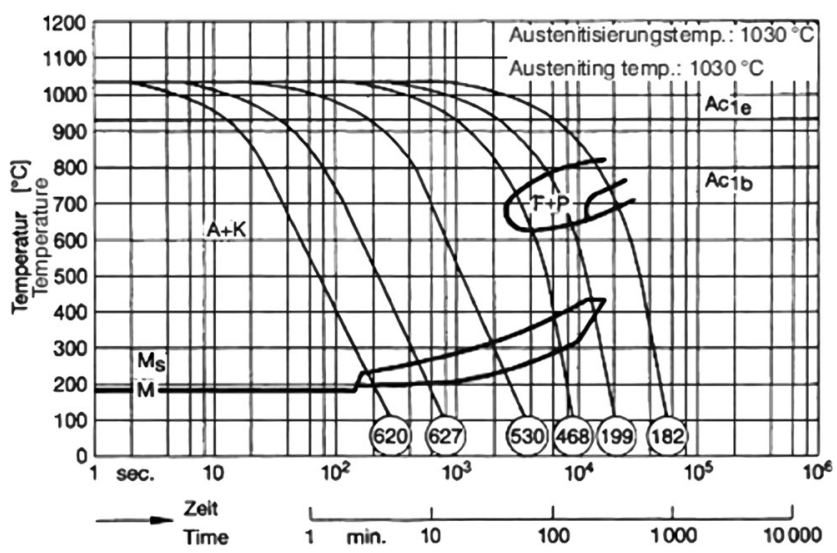

Fig. 3 The 2316ISO-B MOD TTT curves of stainless steel [22]

carried out on tool wear, there have been few papers that focus on the cutting chip color to prediction tool wear $[14,15]$.

\section{Machining principle and tool wear}

\subsection{Tool wear theory}

The cutting tool continues to rub against the chip during cutting, so the contact surface generates high temperatures. At high temperatures, the tool and the chip will chemically diffuse, causing the tool and chip to combine into other compounds, thus reducing tool hardness and toughness. As the cutting continues, dents on the blades will occur, which is known as chemical wear or diffusion wear. However, during cutting, intermittent cutting, vibration, cold and heat changes, and impurities cause the edge to collapse, which is called mechanical wear. Generally, the normal wear process belongs to diffusion wear-in which mild breakage occurs first and then expands into disintegration. When the tool disintegrates, the cutting edge of the tool will be deformed, so the cutting resistance will become stronger, and the cutting temperature will also rise, which causes the tool to wear quickly, in turn causing the tool to lose its cutting ability $[3,4,16]$.

When the cutting tool performs its duties, the contact surface parallel to the material is called the flank surface. Cutting friction will cause the surface to continue to wear. The flank surface

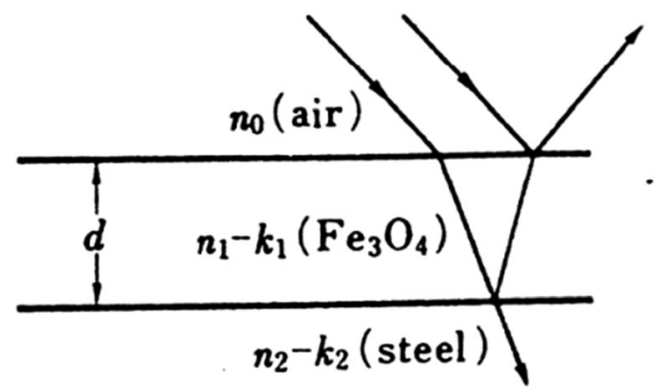

Fig. 4 Machining chip oxidative film model [23] wear area is adjacent to the tool edge, so expansion of wear will increase the cutting resistance and increase the cutting temperature. Eventually, the tool is damaged and loses its function. In order to confirm tool life, the International Standards Organization proposes that when the uniform wear of the flank surface reaches $0.3 \mathrm{~mm}$, this study is based on the ISO-8688-1/ 1994 standard for testing and analysis, or if the surface is peeled off or severely grooved, or the uneven wear reaches $0.6 \mathrm{~mm}$ or more, the extent to which the tool can be used is exceeded, that is, the tool life is over and the tool needs to be replaced. If we use time to separate the tool wear, as shown in Fig. 1, the wear region can be divided into three periods: (1) initial wear rate, (2) uniform wear rate, and (3) accelerating wear rate.

In general, in the research and application of metal machining, in terms of the method of formulating tool life, the Taylor's Cutting Tool Formula is often used to establish the model. In 1906, Taylor [17] proposed the relationship between tool life and machining velocity. The relationship between cutting velocity (V) and tool life (T) can be expressed by the following equation:

$\mathrm{VT}^{\mathrm{n}}=\mathrm{C}$

Where $\mathrm{V}$ is the cutting velocity $(\mathrm{m} / \mathrm{min}) ; \mathrm{T}$ is the tool life, i.e., the actual chip time ( $\mathrm{min})$; $\mathrm{n}$ is the exponent that depends on what materials for the tool and work pieces; and $\mathrm{C}$ is the constant.In the machining process, the machining parameters include the feed per tooth and depth of cutting in addition to the cutting velocity. If all the machining parameters are taken into account in the tool life formula, a more complete tool life formula can be obtained as follows $[18,19]$ :

$\mathrm{VT}^{\mathrm{n}} \mathrm{f}_{\mathrm{z}}^{\mathrm{a}} a p^{\mathrm{b}}=\mathrm{C}$

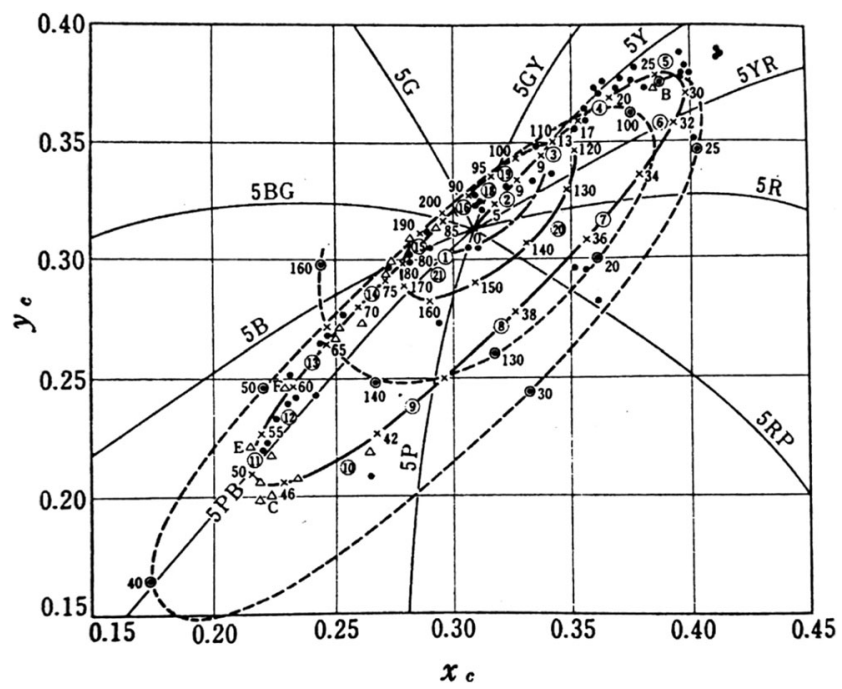

Fig. 5 Chromaticity diagram [23] 
Fig. 6 Color conversion process of the display system

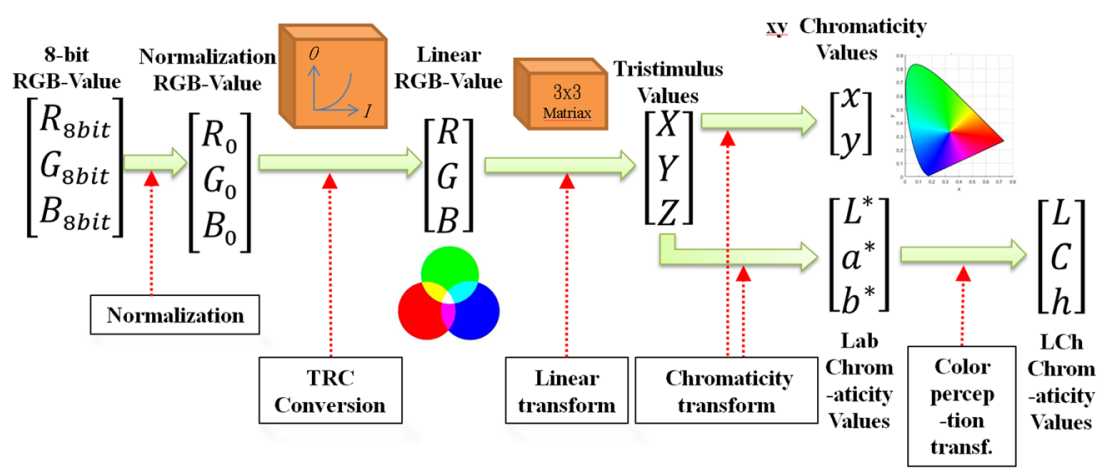

Where $\mathrm{N}$ is the exponent that depends on what materials for the tool and work pieces; $\mathrm{f}_{\mathrm{z}}$ is the feed per tooth ( $\mathrm{mm} /$ tooth); $\mathrm{a}$ is the exponent that depends on what materials for the tool and work pieces; ap is the depth of cutting ( $\mathrm{mm})$, b is the exponent that depends on what materials for the tool and work pieces; and $\mathrm{C}$ is the constant.

\subsection{Stainless steel 2316ISO-B MOD}

Due to the high toughness, high thermal strength, low thermal conductivity, large plastic deformation during cutting, severe work hardening, high heat of cutting, and difficulty in heat dissipation, the stainless steel materials will cause high cutting temperature at its tip and be seriously as well as easily sticks on the cutting edge, thus producing accumulated scums, accelerating tool wear, and affecting the roughness of machining surface.
Stainless steel must contain at least $11 \%$ chromium in terms of the standard definition. The chromium element has the function of forming a protective layer of chromium oxide on the surface of the steel. The chromium oxide layer can insulate metals from contact with the external environment, making the material less susceptible to oxidative deterioration. Stainless steel is mainly classified into different types based on the crystal structure and the strengthening mechanism, such as the ferrite iron system, the Ma Tian iron system, the Worthian iron system, the precipitation hardening system, and the two-way stainless steel [20, 21].

The stainless steel 2316ISO-B MOD used in this study belongs to the Ma Tian scattered iron series stainless steel in terms of structure. It is mainly used as the molding material for production of plastic products. It is widely used in injection molds, mold inserts, coaxial shells for blow molds, etc.. The material properties, physical properties, and heat treatment
Fig. 7 Experimental research process

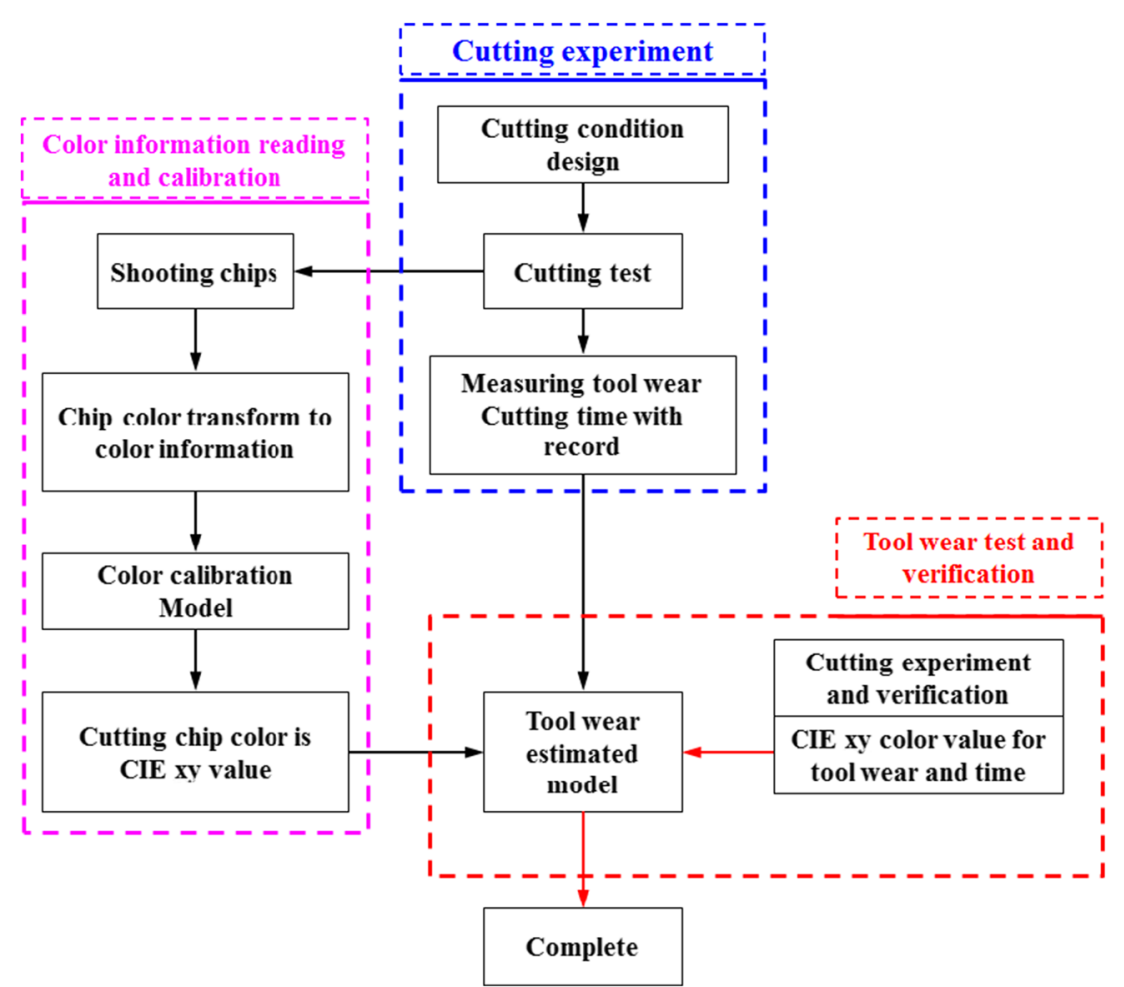




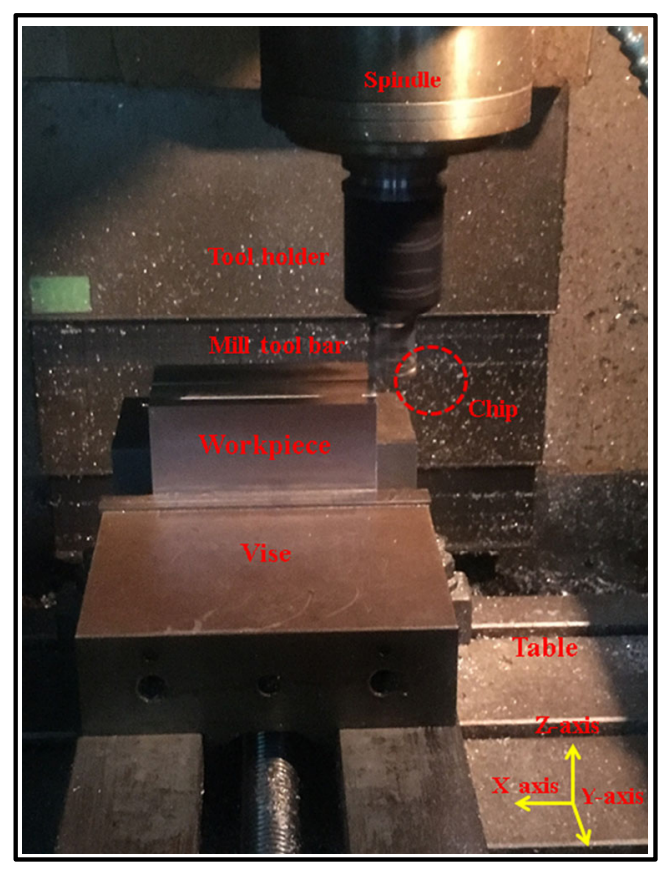

Fig. 8 Machining center equipment

methods of 2316ISO-B MOD stainless steel are shown in Tables 1 to 2 and Figs. 2 and 3.

\subsection{Machining chip colors and oxidative film model}

When cutting steel materials, the high-speed friction between the tool and the cutting materials will generate a lot of cutting heat. The chips will be heated rapidly by the heat of cutting
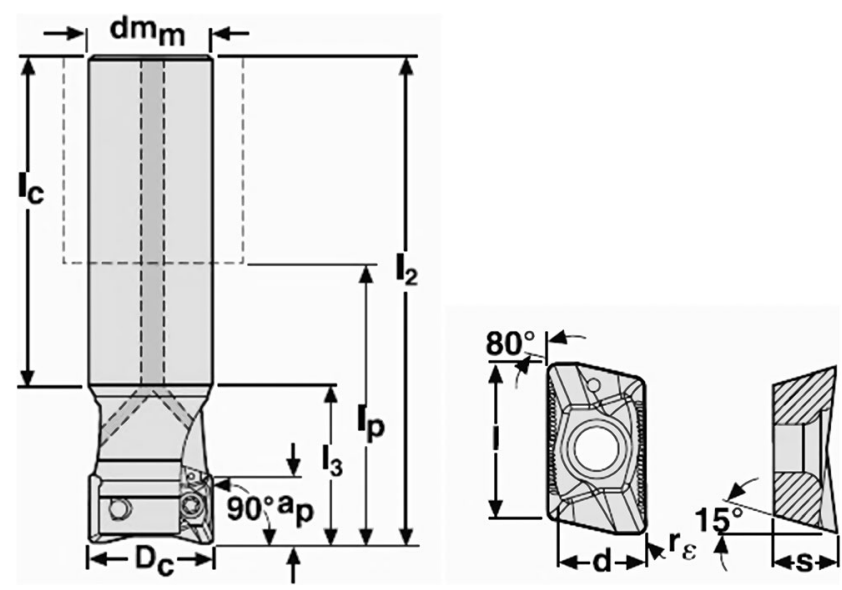

Fig. 10 Tool holders and cutting inserts

and will be rapidly cooled in the air after being cut away from the base. This phenomenon causes the chips to produce different colorings of oxidative films on the surface. The color of the oxidative film is affected by the thickness (d) of the oxidative film, the refractive index (n) of the oxidative film and the base material, and the absorption coefficient $(\mathrm{k})$, as shown in Fig. 4. The machining color during the cutting process changes in the following order: yellow $\rightarrow$ yellow brown $\rightarrow$ brown $\rightarrow$ purple $\rightarrow$ deep purple or dark blue $\rightarrow$ blue $\rightarrow$ light blue $\rightarrow$ blue green $\rightarrow$ yellow green $\rightarrow$ dark red.

Shown in Fig. 5, the relationship between the thickness of the chip oxidation film and the chromaticity coordinate point shows a solid continuous line. The lines extending radially from the center indicate the hues such as $\mathrm{Y}$ (yellow), R (red), P (purple), B (blue), and G (green).
Fig. 9 CCD industrial camera equipment

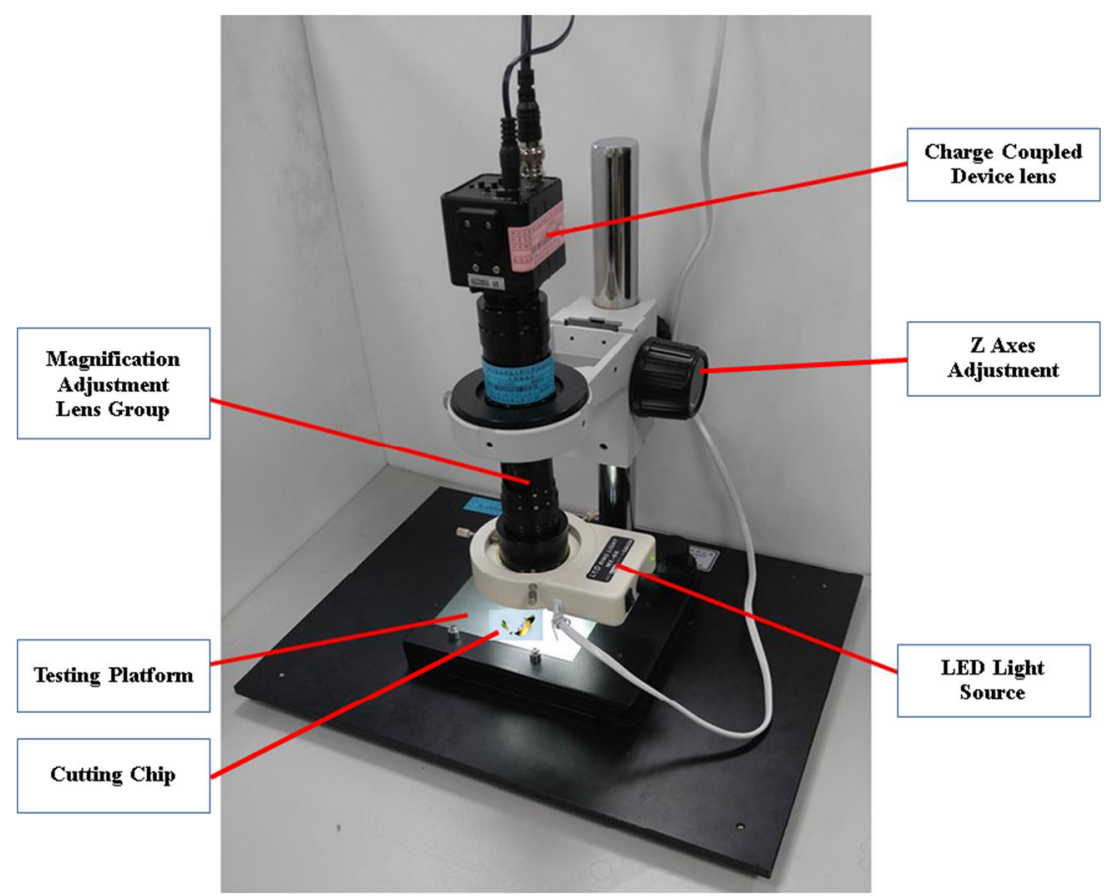




\section{Measurement equipment development and create model}

The machining chip color and the measurement equipment data are mainly created by calculation of the numerical conversion of RGB values, XYZ tristimulus values, xy chromaticity values, etc., and for the display, the system accepts the electronic signals, and according to the signal strength, color mixture can be obtained. The corresponding color will appear on the display screen, so the numerical conversion of the display color will be different from that of the mathematically calculated mode of the colorimetry. The process of color space conversion will be described in details as shown below. The process of color space transformation of the display system is shown in Fig. 6.

The main process for establishing the machining color and measurement equipment data is shown as follows.

\section{Step 1. Normalization}

The color signals initially input on the display is $\left[\mathrm{R}_{8-\mathrm{bit}} \mathrm{G}_{8-}\right.$ bit $\mathrm{B}_{8 \text {-bit }}$ 8-bit RGB signal values, the numeric range of the three primary colors are all $0 \sim 255$, and after conversion they become $\left[R_{0} G_{0} B_{0}\right]$, the normalized RGB signal values.

$I_{0}=\frac{I}{255}$

where $\mathrm{I}_{0}=\mathrm{R}_{0}, \mathrm{G}_{0}, \mathrm{~B}_{0}$ are the normalized $\mathrm{RGB}$ signal values and $I=R_{8-b i t}, G_{8-b i t}, B_{8-b i t}$ are the new 8-bit RGB signal values.

\section{Step 2. TRC transformation}

TRC means Tone Reproduction Cure, indicating the relationship between the signal value and brightness of the display input, while the normalized RGB signal values $\left[\mathrm{R}_{0} \mathrm{G}_{0} \mathrm{~B}_{0}\right]$ are converted into linear RGB values [R G B]; in general, the

Table 3 Tool holders and cutting inserts specification table

\begin{tabular}{ccr} 
Tool holder (R217.69-3232.0-18-3AN) & \\
$\mathrm{a}_{\mathrm{p}}$ & Cutting depth (mm) & 17 \\
$\mathrm{D}_{\mathrm{c}}$ & Tool outer diameter $(\mathrm{mm})$ & 32 \\
$\mathrm{dm}_{\mathrm{m}}$ & Tool holder diameter $(\mathrm{mm})$ & 32 \\
$\mathrm{l}_{\mathrm{p}}$ & Tool holder length $(\mathrm{mm})$ & 170 \\
$\mathrm{l}_{2}$ & Total length $(\mathrm{mm})$ & 210 \\
$\mathrm{~N}$ & Revolution speed $(\mathrm{rpm})$ & 11,100 \\
Cutting insert & XOMX180631TR-ME13 F40M) \\
Coated PVD + TiAlN & \\
Ra & Rake angle $(\circ)$ & 30 \\
$r_{\varepsilon}$ & Nose radius (mm) & 3.1 \\
EA & clearance angle $(\circ)$ & 15 \\
\hline
\end{tabular}

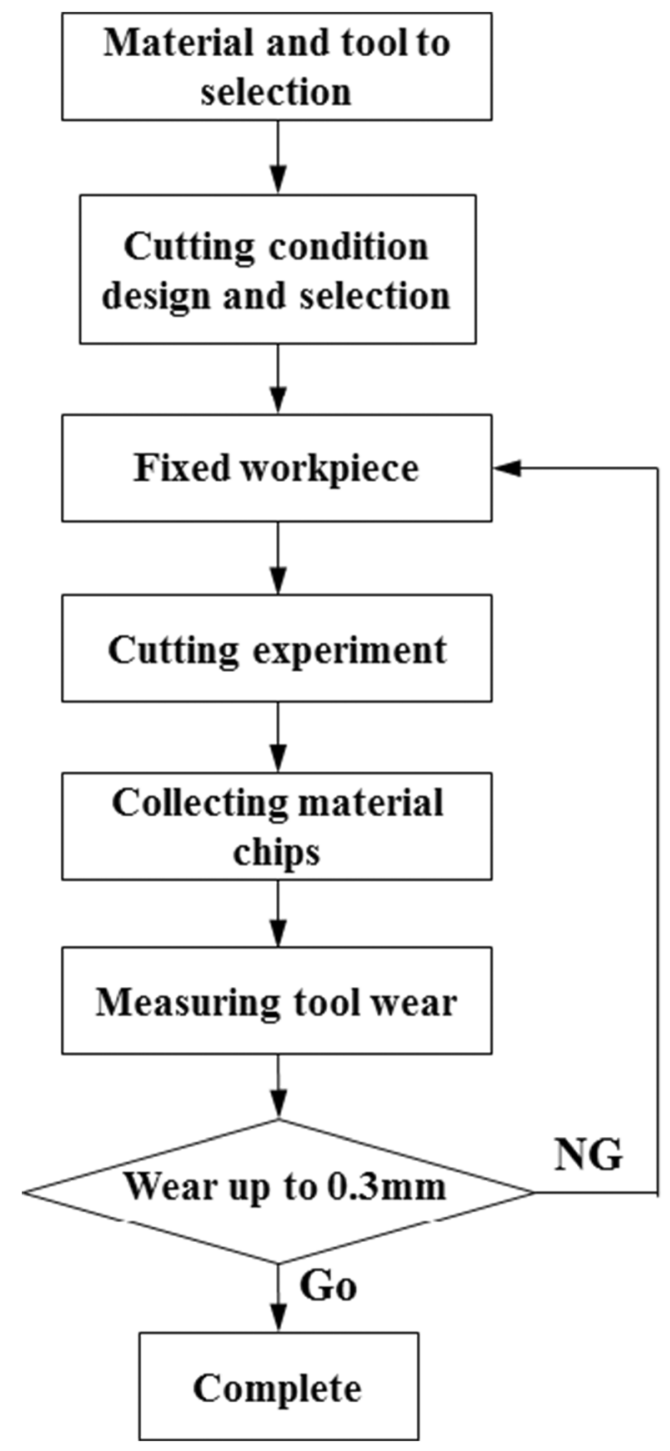

Fig. 11 Machining experiment flow

display will adopt the value $\gamma$ to normalize the relationship between the RGB values and the linear RGB ones. The value $\gamma$ will change due to different monitor specifications. Generally, it falls between 1.8 and 2.4.

$$
\begin{aligned}
& \mathrm{R}=\left(R_{0}\right)^{\gamma_{R}} \\
& \mathrm{G}=\left(G_{0}\right)^{\gamma_{G}} \\
& \mathrm{~B}=\left(B_{0}\right)^{\gamma_{B}}
\end{aligned}
$$

Table 4 Parameter table of processing experiment

\begin{tabular}{ll}
\hline Cutting velocity & $500 \mathrm{~m} / \mathrm{min}$ \\
Feed per tooth & $0.1 \mathrm{~mm} /$ tooth \\
Cutting depth & $0.5 \mathrm{~mm}$ \\
Cutting width & $20 \mathrm{~mm}$ \\
Cutting time & $0.2746 \mathrm{~min}$ \\
Milling method & Single-blade milling \\
Cutting fluid & None \\
\hline
\end{tabular}


Fig. 12 Color information reading and correction process

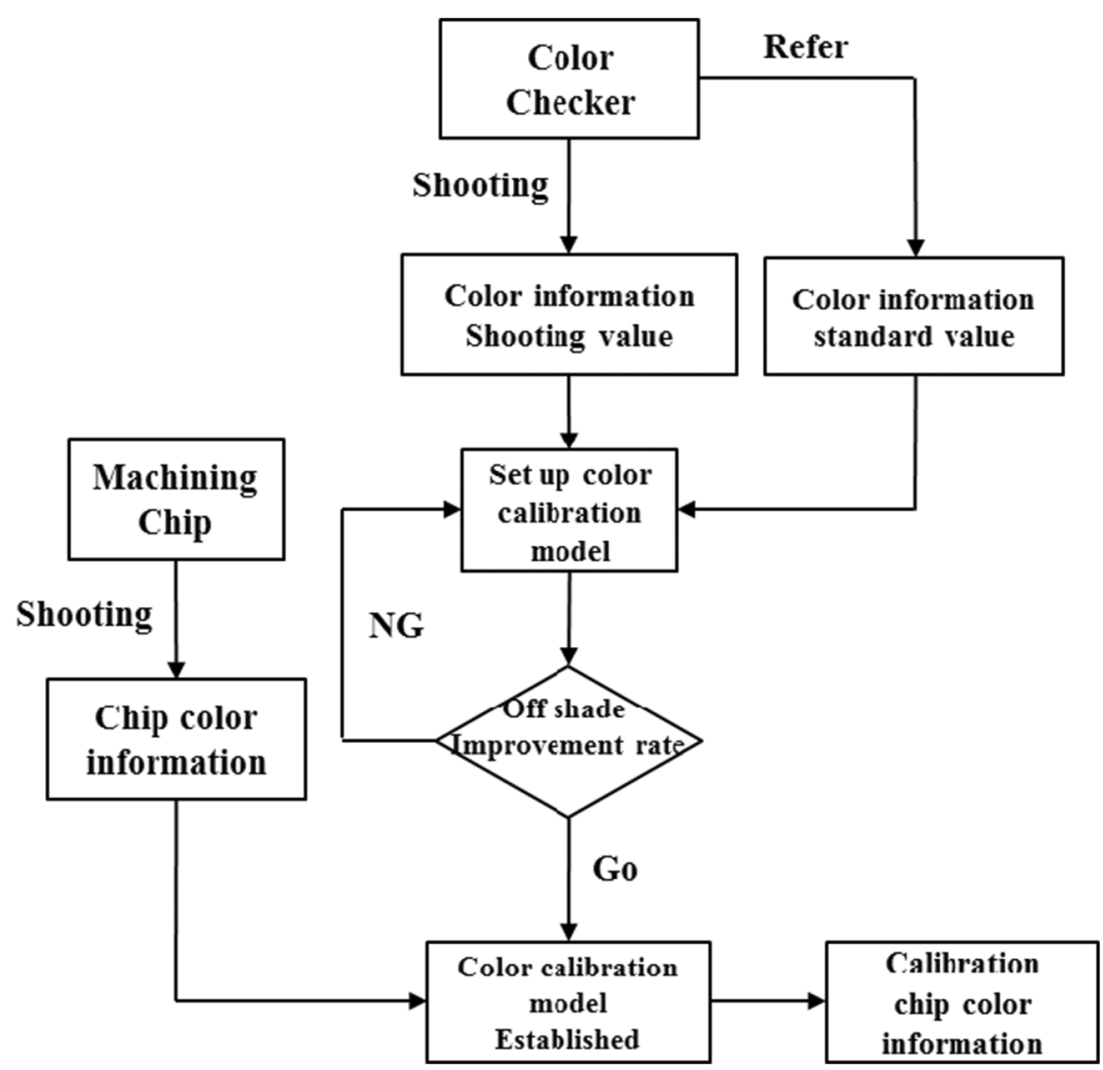

where R, G, and B indicate the values of linear RGB signal.

$\gamma_{R}, \gamma_{G}, \gamma_{B}$, correspond to the value $\gamma$ of $\mathrm{R}, \mathrm{G}, \mathrm{B}$.

\section{Step 3. Linear transformation}

Linear transformation means a step that converts the RGB values [R G B] into three stimulus values, which process uses a computational $3 \times 3$ matrix, and the $3 \times 3$ transformation matrix will vary with different standard

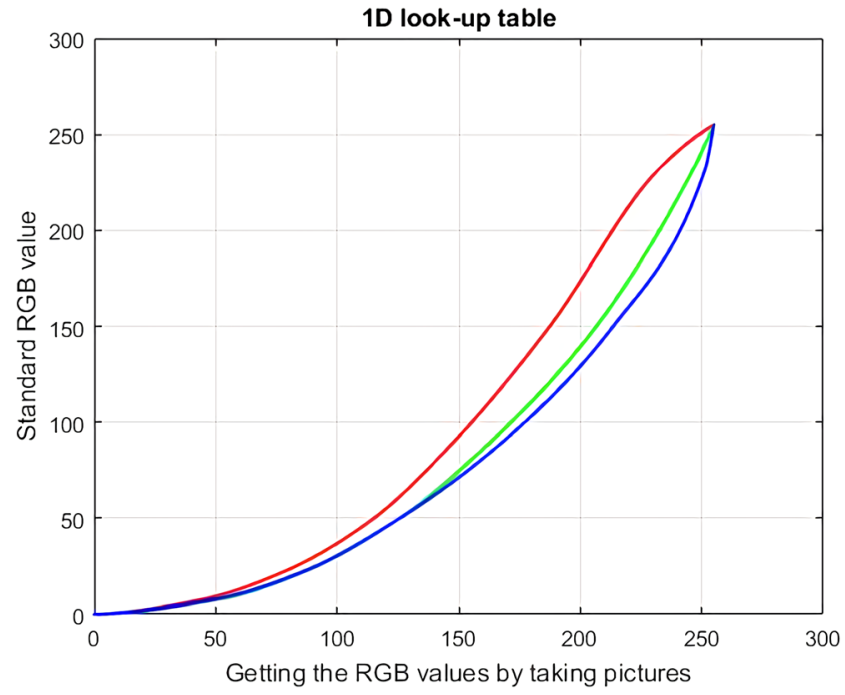

Fig. 13 One-dimensional comparison table (1D LUT) displays. The standard for different types of displays is described in the Eq. 4.

$$
\left[\begin{array}{l}
X \\
Y \\
Z
\end{array}\right]=M\left[\begin{array}{l}
R \\
G \\
B
\end{array}\right]
$$

where $X, Y$, and $Z$ are tristimulus values, while $M$ is a $3 \times 3$ linear transformation matrix.

\section{Step 4. Chromaticity transformation}

The XYZ tristimulus value [XYZ] can be transformed into the $x$ y chromaticity value $[x$ y] based on Eq. 5 and be displayed in the CIExy chromaticity diagram or transformed into the $\mathrm{L}^{*} \mathrm{a} * \mathrm{~b}^{*}$ chromaticity value. [L*a* $\left.\mathrm{b}^{*}\right]$ is displayed in the figure of the CIE LAB color space.

$$
\begin{aligned}
& \mathrm{L}^{*}=116 \mathrm{f}\left(\frac{Y}{Y_{n}}\right)-16 \\
& \mathrm{a}^{*}=500\left[\mathrm{f}\left(\frac{X}{X_{n}}\right)-\mathrm{f}\left(\frac{Y}{Y_{n}}\right)\right] \\
& \mathrm{b}^{*}=500\left[\mathrm{f}\left(\frac{Y}{Y_{n}}\right)-\mathrm{f}\left(\frac{Z}{Z_{n}}\right)\right] \\
& \mathrm{f}\left(\frac{I}{I_{n}}\right)=\left(\frac{I}{I_{n}}\right)^{\frac{1}{3}} \text {, when }\left(\frac{I}{I_{n}}\right)>0.008856 \\
& \mathrm{f}\left(\frac{I}{I_{n}}\right)=7.787\left(\frac{I}{I_{n}}\right)+\frac{16}{116} \text {, when }\left(\frac{I}{I_{n}}\right) \leq 0.008856
\end{aligned}
$$

where $\mathrm{I} / \mathrm{I}_{\mathrm{n}}=\mathrm{X} / \mathrm{X}_{\mathrm{n}}=\mathrm{Y} / \mathrm{Y}_{\mathrm{n}}=\mathrm{Z} / \mathrm{Z}_{\mathrm{n}}$ 
Fig. 14 Test and verification process of tool wear model $\multimap$ Group $1 \rightarrow$ Group $2 \rightarrow$ Group 3

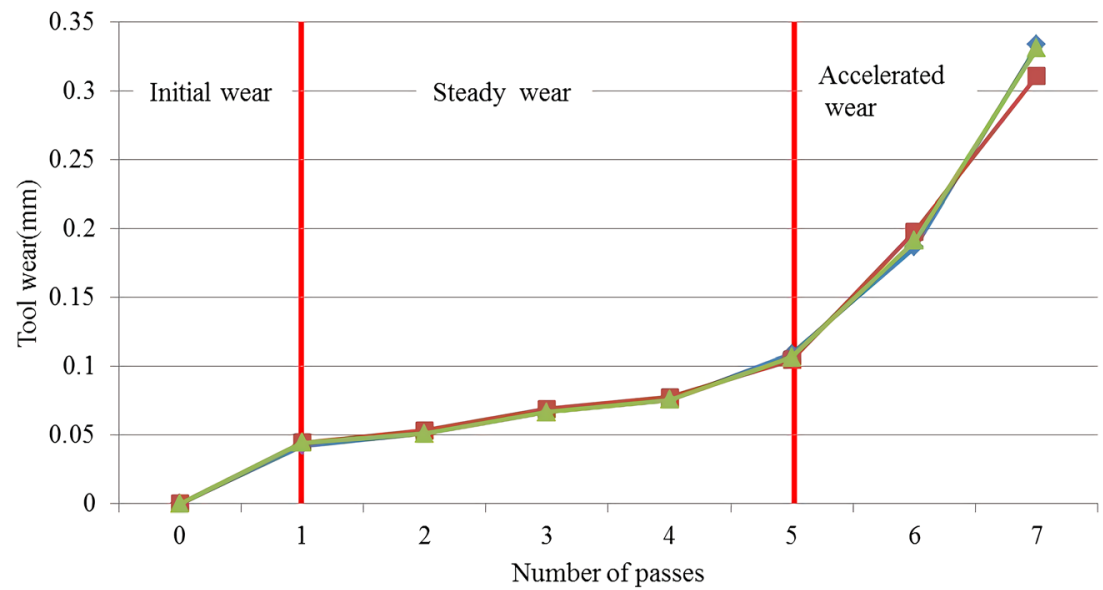

$\mathrm{X}, \mathrm{Y}, \mathrm{Z}$ are the tristimulus value of an object.

$X_{n}, Y_{n}, Z_{n}$ the benchmark-white tristimulus value, and the tristimulus value will be produced with different kinds of light sources.

\section{Step 5. Color perception transformation}

This step transforms the $\left[\mathrm{L}^{*} \mathrm{a}^{*} \mathrm{~b}^{*}\right]$ of the CIE LAB color space into the $[\mathrm{L} \mathrm{C} \mathrm{h}]$ of color perception. $\mathrm{L}, C_{\mathrm{ab}}{ }^{*}$, and $h_{\mathrm{ab}}$ indicate the brightness, chrome, and hue, respectively.
$C_{\mathrm{ab}}=\sqrt{\left[\left(a^{*}\right)^{2}+\left(b^{*}\right)^{2}\right]}$

$h_{\mathrm{ab}}=\tan ^{-1}\left(\left|\frac{b^{*}}{a^{*}}\right|\right)$

where the calculation of $h_{\mathrm{ab}}$ produces different combinations of positive or negative values of $\mathrm{a}^{*}$ and $\mathrm{b}^{*}$.

Take $\left(\frac{b^{*}}{a^{*}}\right)$ as the absolute value, and then find the appropriate angle based on its quadrant coordinates.
Fig. 15 Human-machine interface of tool wear determination system

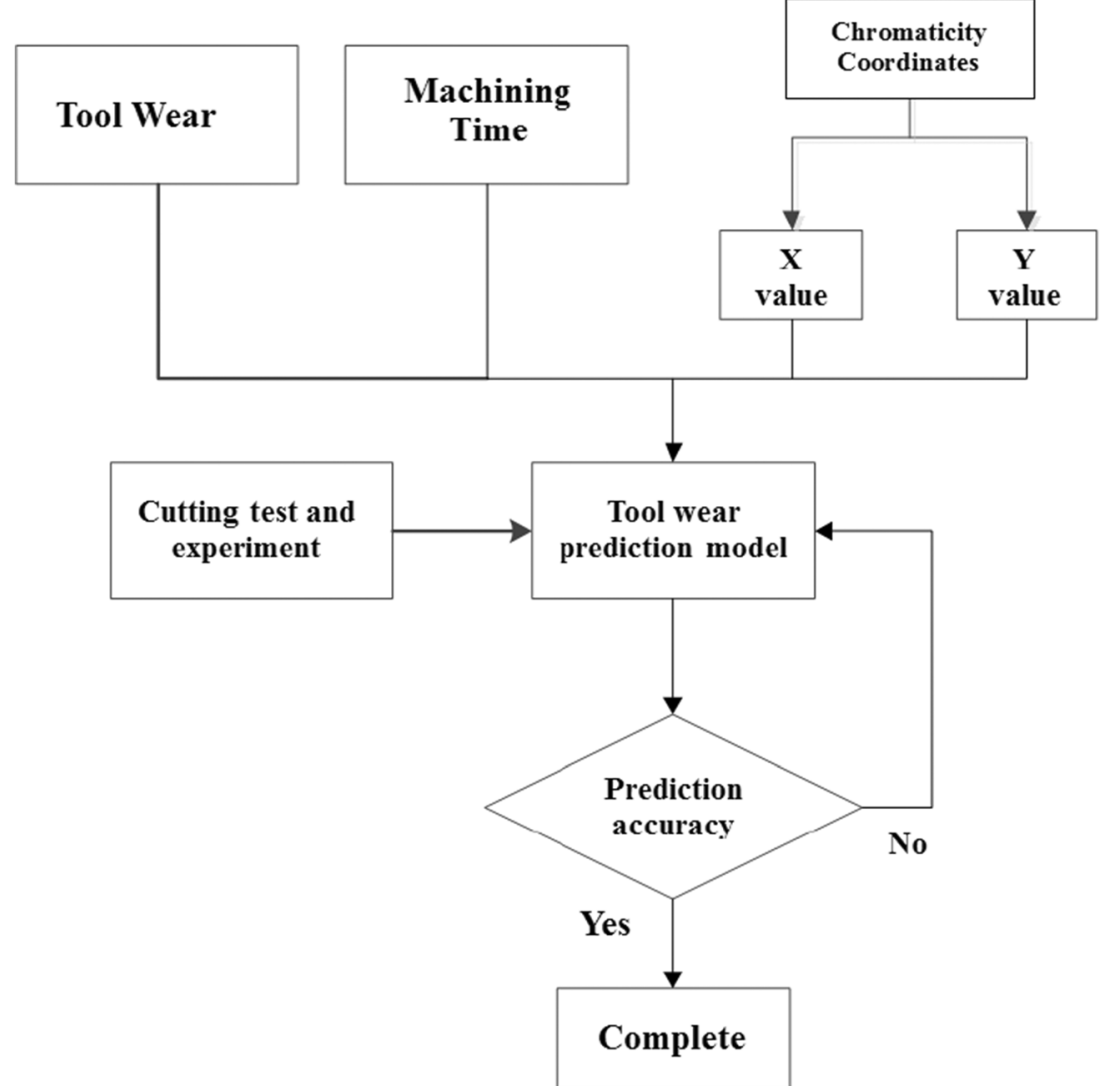




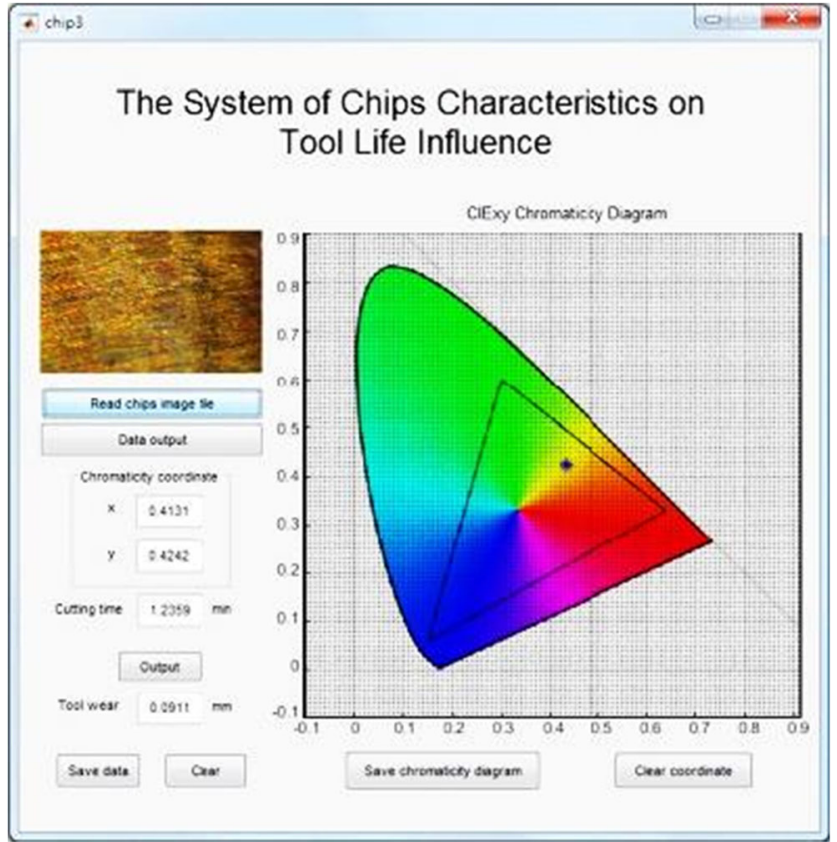

Fig. 16 Cutting tool wear curve

\section{Experimental process and equipment}

The experimental process of this study is shown in Fig. 7. It is primarily divided into three phases: machining experiment, color information reading and correction, and tool wear determination and verification. Details are explained as follows.

This study used a machining center for milling, where the experimental equipment as shown in Fig. 8. the 3 axes, $\mathrm{X}, \mathrm{Y}$, and Z, moved on travel of $1000 \mathrm{~mm}, 800 \mathrm{~mm}$, and $700 \mathrm{~mm}$, respectively. The feed velocity was from 1 to $20,000 \mathrm{~mm} / \mathrm{min}$, and the maximum revolution of the main spindle was $14,000 \mathrm{rpm}$. Figure 9 is a CCD industrial camera equipment.

The cutting tool used in the cutting experiment is tool holders and cutting inserts, as shown in Fig. 10 and Table 3.

\subsection{Machining experiment}

The process and parameters at the phase in this study are shown in Fig. 11 and Table 4. Refer to the recommended chip parameters in the tool catalog, and enter the parameters into the Taylor's formula for calculation of tool wear, and calculate the results based on the actual situation, and adjust the values

Fig. 17 Cutting tool wear and chips of group 1

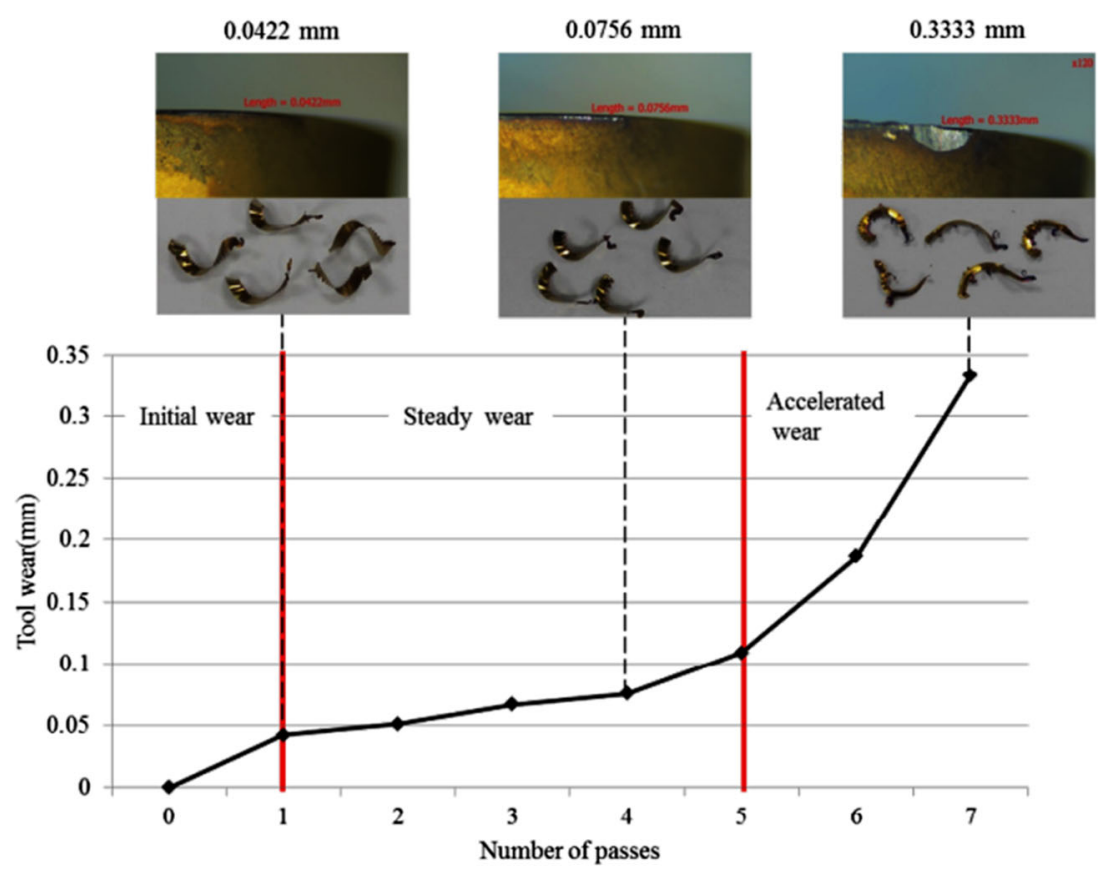

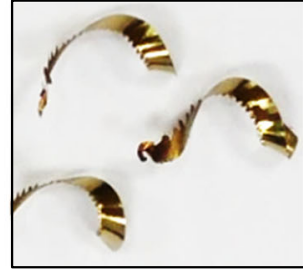

No.1st test

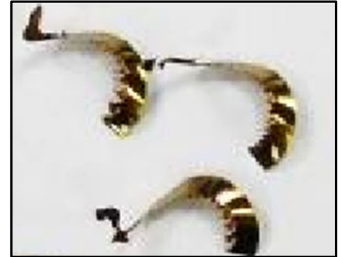

No.4th test

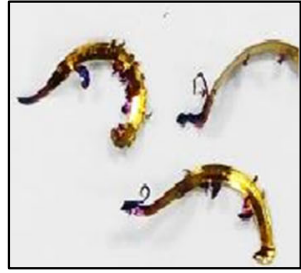

No.7th test 
Fig. 18 Cutting tool wear and chips of group 2

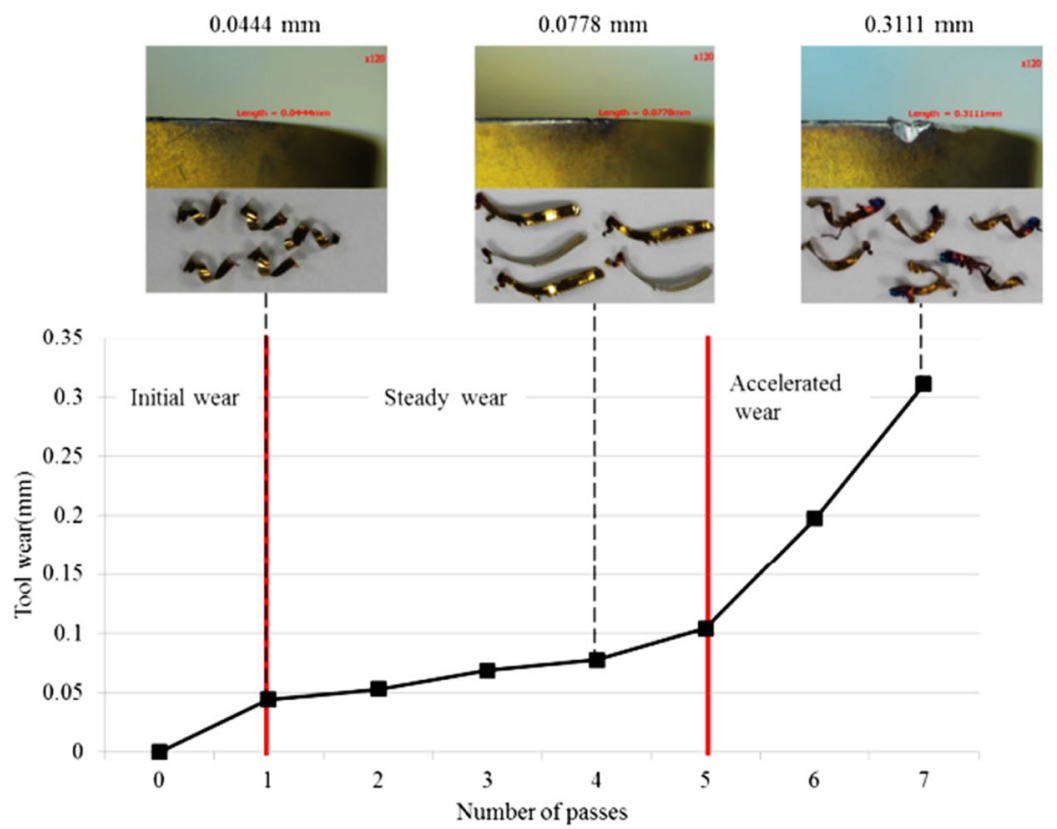

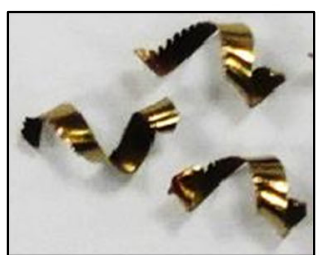

No.1st test

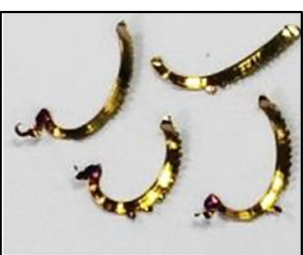

No.4th test

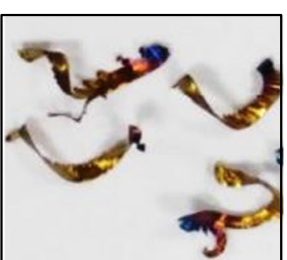

No.7th test to get the most appropriate cutting experimental parameters. The cutting velocity $\mathrm{V}$ recommended by the reference tool catalog is $105 \sim 130(\mathrm{~m} / \mathrm{min})$, the feed rate per blade $\mathrm{fz}$ is $0.1 \sim 0.2$ (mm/tooth), and the part cutting depth ap is made by Eq. 9 by calculation.

$f_{\mathrm{z}}=\frac{t_{c} \times 2 r_{\varepsilon}}{2 \times \sqrt{a_{p} \times 2 r_{\varepsilon}-a_{p}^{2}}}$

where $f_{z}$ means feed per tooth ( $\mathrm{mm} /$ tooth), $t_{c}$ means chip thickness $(\mathrm{mm})$ that is a fixed value $0.06 \mathrm{~mm}, r_{\varepsilon}$ means nose radius $(\mathrm{mm})$ that is a fixed value $3.1 \mathrm{~mm}$, and $\mathrm{a}_{\mathrm{p}}$ means cutting depth (mm). To get the cutting depth $\mathrm{a}_{\mathrm{p}}$, first convert Eq. 9 into

$a_{\mathrm{p}}{ }^{2}-2 r_{\varepsilon} \times a_{\mathrm{p}}+\left(\frac{t_{\mathrm{c}} \times r_{\varepsilon}}{f_{\mathrm{z}}}\right)^{2}=0$

The chip thickness is $0.06 \mathrm{~mm}$; refer to the stainless steel material of the tools catalog, substitute chip thickness, and condition into Eq. 11 to solve depth of cutting.

$a_{\mathrm{p}}=\frac{2 r_{\varepsilon} \pm \sqrt{\left(-2 r_{\varepsilon}\right)^{2}-4\left(\frac{t_{\mathrm{c}} \times r_{\varepsilon}}{f_{\mathrm{z}}}\right)}}{2}$
Use Eq. 11 to calculate the depth of cutting $\mathrm{a}_{\mathrm{p}}: 0.15 \sim$ $0.63 \mathrm{~mm}$.

\subsection{Color information Reading and correction}

This study established a set of color correction models to make the chip colors obtained by chip photographing be standardized. It can be used to evaluate the color reproduction ability and at the same time allows for the sharing of data with other photographing systems. The process shown in Fig. 12 below provides a detailed description.

In the calibration of the measuring device, apply the gray color block in the standard color checker passport of the standard color information to obtain the RGB shooting value, and set it as the $x$-axis, and the $y$-axis is set to the RGB standard value attached to the color checker. Establish a one-dimensional comparison table (1D LUT) model that converts RGB shot values to standard values, as shown in Fig. 13. And then input the color patch RGB shooting values into the onedimensional comparison table (1D LUT) and converted into standard values R', G', B'. Use the color correction 
Fig. 19 Cutting tool wear and chips of group 3

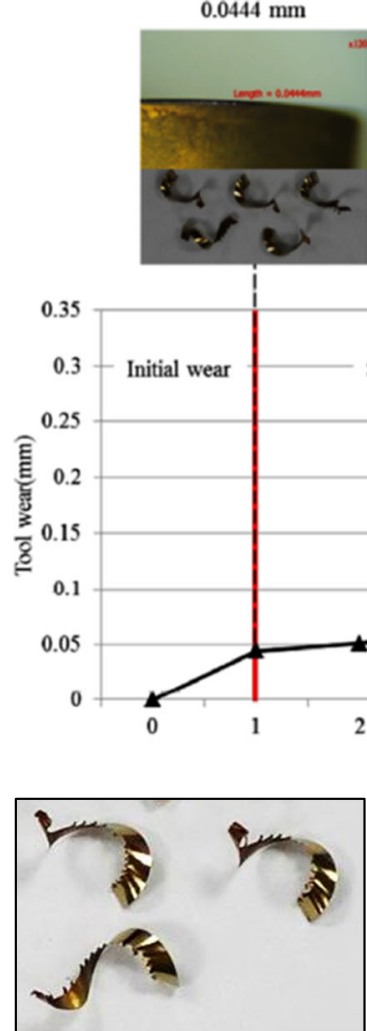

No.1st test
$0.0756 \mathrm{~mm}$

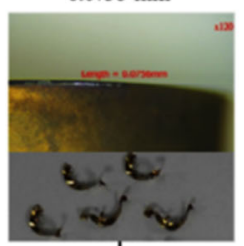

$0.3311 \mathrm{~mm}$

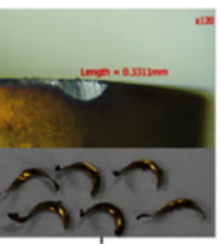

i
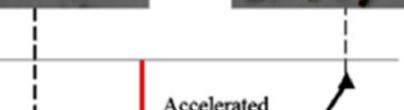

Accelerated wear

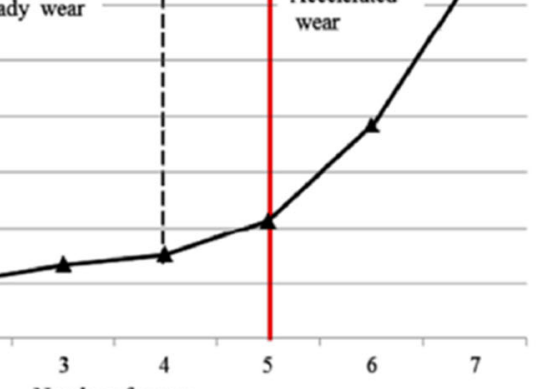

Number of passes

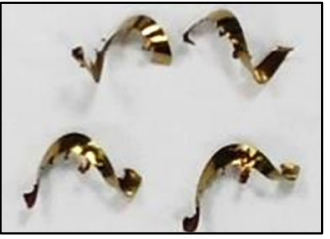

No.4th test

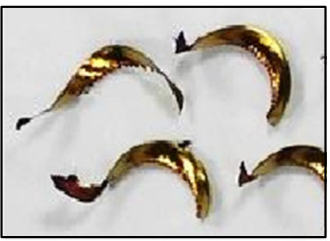

No.7th test system established in the study, and we can improve the color difference of the camera from $\Delta \mathrm{E}_{-} \mathrm{ab}^{\wedge *}=18.6$ to 2.9. According to the color difference specification of the National Bureau of Standards (NBS), the smaller color difference of the third level is within an acceptable range of the upper middle level.

Establish a regression equation for converting the standard value $R^{\prime} G^{\prime} B$ ' into the color space CIE LAB as exemplified by Eqs. 1-3, and then convert it into the matrix type of Eq. 4, and convert the previously obtained $\mathrm{R}^{\prime} \mathrm{G}^{\prime} \mathrm{B}^{\prime}$ value with color checker. The CIE LAB standard value attached to the passport color card is applied by Eq. 4 to calculate the value of the color correction matrix $\mathrm{M}$ and thus establish the color correction model, which is evaluated by the color reproduction capability specification developed by the National Bureau of Standards (NBS) [10]. If the color correction ability is insufficient, please improve your photographing surroundings until the color difference level reaches the target level, and finally take the material chip to obtain the parameters of the tool wear.
$\mathrm{L}^{*}=\mathrm{a}_{0}+\mathrm{a}_{1} \mathrm{R}^{\prime}+\mathrm{a}_{2} \mathrm{G}^{\prime}+\mathrm{a}_{3} \mathrm{~B}^{\prime}+\mathrm{a}_{4} \mathrm{R}^{\prime} \mathrm{G}^{\prime}+\mathrm{a}_{5} \mathrm{R}^{\prime} \mathrm{B}^{\prime}$

$$
\begin{aligned}
& +\mathrm{a}_{6} \mathrm{G}^{\prime} \mathrm{B}^{\prime}+\mathrm{a}_{7} \mathrm{R}^{\prime 2}+\mathrm{a}_{8} \mathrm{G}^{2}+\mathrm{a}_{9} \mathrm{~B}^{\prime 2}+\mathrm{a}_{10} \mathrm{R}^{\prime} \mathrm{G}^{\prime} \mathrm{B}^{\prime} \\
& +\mathrm{a}_{11} \mathrm{R}^{\prime 3}+\mathrm{a}_{12} \mathrm{G}^{\prime 3}+\mathrm{a}_{13} \mathrm{~B}^{\prime 3}
\end{aligned}
$$

$$
\begin{aligned}
\mathrm{a}^{*}= & \mathrm{b}_{0}+\mathrm{b}_{1} \mathrm{R}^{\prime}+\mathrm{b}_{2} \mathrm{G}^{\prime}+\mathrm{b}_{3} \mathrm{~B}^{\prime}+\mathrm{b}_{4} \mathrm{R}^{\prime} \mathrm{G}^{\prime}+\mathrm{b}_{5} \mathrm{R}^{\prime} \mathrm{B}^{\prime} \\
& +\mathrm{b}_{6} \mathrm{G}^{\prime} \mathrm{B}^{\prime}+\mathrm{b}_{7} \mathrm{R}^{\prime 2}+\mathrm{b}_{8} \mathrm{G}^{\prime 2}+\mathrm{b}_{9} \mathrm{~B}^{\prime 2}+\mathrm{b}_{10} \mathrm{R}^{\prime} \mathrm{G}^{\prime} \mathrm{B}^{\prime} \\
& +\mathrm{b}_{11} \mathrm{R}^{\prime 3}+\mathrm{b}_{12} \mathrm{G}^{\prime 3}+\mathrm{b}_{13} \mathrm{~B}^{\prime 3}
\end{aligned}
$$

$$
\begin{aligned}
\mathrm{b}^{*}= & \mathrm{c}_{0}+\mathrm{c}_{1} \mathrm{R}^{\prime}+\mathrm{c}_{2} \mathrm{G}^{\prime}+\mathrm{c}_{3} \mathrm{~B}^{\prime}+\mathrm{c}_{4} \mathrm{R}^{\prime} \mathrm{G}^{\prime}+\mathrm{c}_{5} \mathrm{R}^{\prime} \mathrm{B}^{\prime} \\
& +\mathrm{c}_{6} \mathrm{G}^{\prime} \mathrm{B}^{\prime}+\mathrm{c}_{7} \mathrm{R}^{\prime 2}+\mathrm{c}_{8} \mathrm{G}^{\prime 2}+\mathrm{c}_{9} \mathrm{~B}^{\prime 2}+\mathrm{c}_{10} \mathrm{R}^{\prime} \mathrm{G}^{\prime} \mathrm{B}^{\prime} \\
& +\mathrm{c}_{11} \mathrm{R}^{\prime 3}+\mathrm{c}_{12} \mathrm{G}^{\prime 3}+\mathrm{c}_{13} \mathrm{~B}^{\prime 3}
\end{aligned}
$$


Fig. 20 Cutting wear and chromaticity coordinate points of group 1

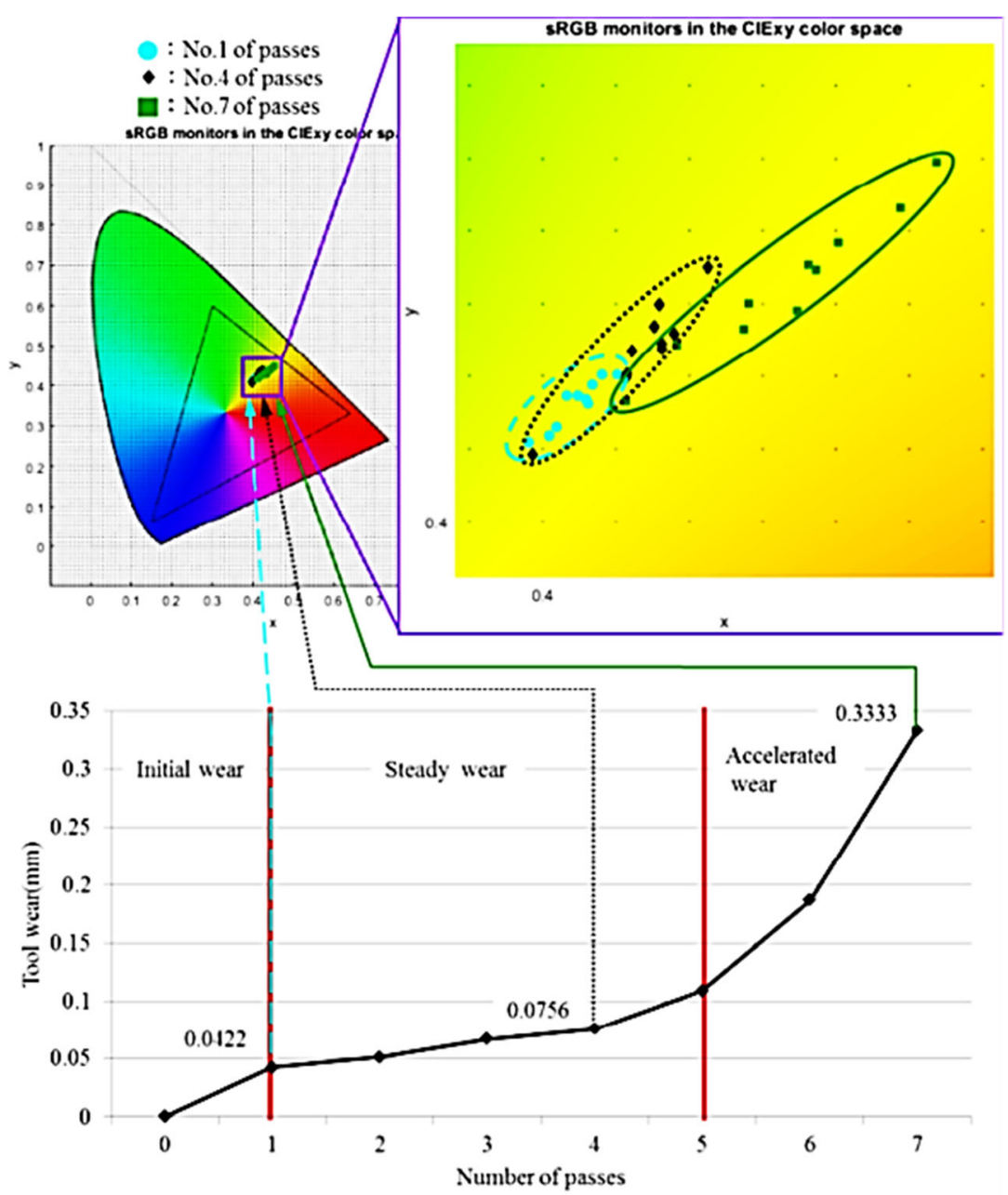

\subsection{Tool wear determination and verification}

Figure 14 shows the experimental process of this phase. Apply the tool wear, cutting time, and chip color information CIExy chromaticity coordinates to establish the wear determination model by the use of the inverse transfer neural network. The data distribution is $70 \%$ for model training, $15 \%$ for testing, and $15 \%$ for verifying [11]; if the model error is too large, adjust the number of neurons, transfer functions, or increase the number of modeling parameters to improve the accuracy of the prediction model.

\subsection{Human-machine interface of tool wear determination system}

In order to facilitate the user to observe the wear of the cutting tool, this study establishes a human-machine interface, and by the use of industrial cameras, the user can shoot the chips. The user only needs to input the image of the cutting chip and the cutting time to get the tool immediately. The predicted value of wear is shown in Fig. 15.

\section{Results and discussion}

\subsection{Repeated test for cutting tool wear}

The tool life test was performed three times; the fundamental purpose was to confirm the repeatability of experimental data; the three groups of cutting tool wear curves were compared, as shown in Fig. 16. The cutting tool wear has the same curvilinear trend; the average error value is shown in Table 4. The largest difference in the wear value of cutting test occurs in No. 7 cutting test for final wear loss, the tool flank wear has reached $\mathrm{V}_{\mathrm{B}}=0.3 \mathrm{~mm}$, the value difference percentage is $6.66 \%$, 
Fig. 21 Cutting wear and chromaticity coordinate points of group 2

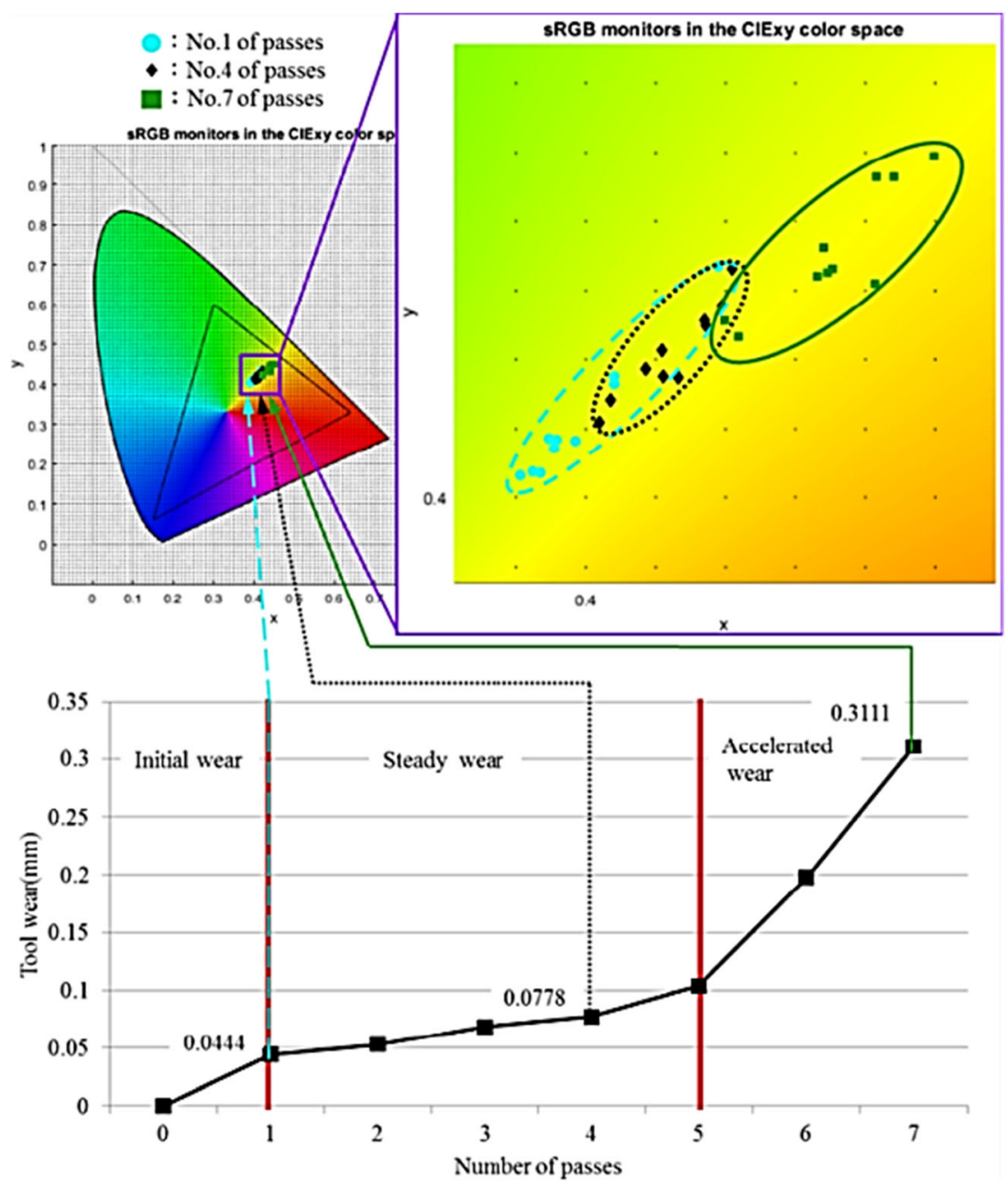

and the minimum difference is the $2.83 \%$ of No. 4 cutting. After repeated tests and experimental analysis, the average error of repeatability is $4.5 \%$, meaning the parameters of this cutting test have enough accuracy for create the prediction model of this study.

\subsection{The relationship between tool wear and Taylor's tool life}

The same parameters are used for three tests to observe the repeatability of three tests. Figures 17,18 , and 19 show the relationship between the cutting tool wear loss and chip morphology obtained in the cutting tests, which is established according to Taylor's lifetime curve. This study performs three groups of cutting, cutting 7 times each group, resulting in 21 wear values and material chips. According to experimental observation, the shape of chips in the first five cuttings is basically consistent, mainly because of the even wear of cutting tool. In the sixth cutting, the cutting tool has entered the quick wear region; the cutting edge and tool flank are worn quickly; the chips are influenced, leading to different shapes and colors during cutting.

\subsection{The relationship between chip color and tool wear}

The chips can be collected and analyzed immediately in the experimental process; 10 pieces are sampled from each group and shot; there are 210 CIExy chromaticity coordinate values of chips; the relationship between the wear loss of cutting tool and chip color information is shown in Figs. 20, 21, and 22; the findings are given below.

1. The $x$ and $y$ coordinate values in the CIExy chromaticity coordinate graph increase gradually with cutting tool wear loss.

2. The range of chromaticity coordinate points of chips resulted from initial cutting is smaller, and the range of 
Fig. 22 Cutting wear and chromaticity coordinate points of group 3

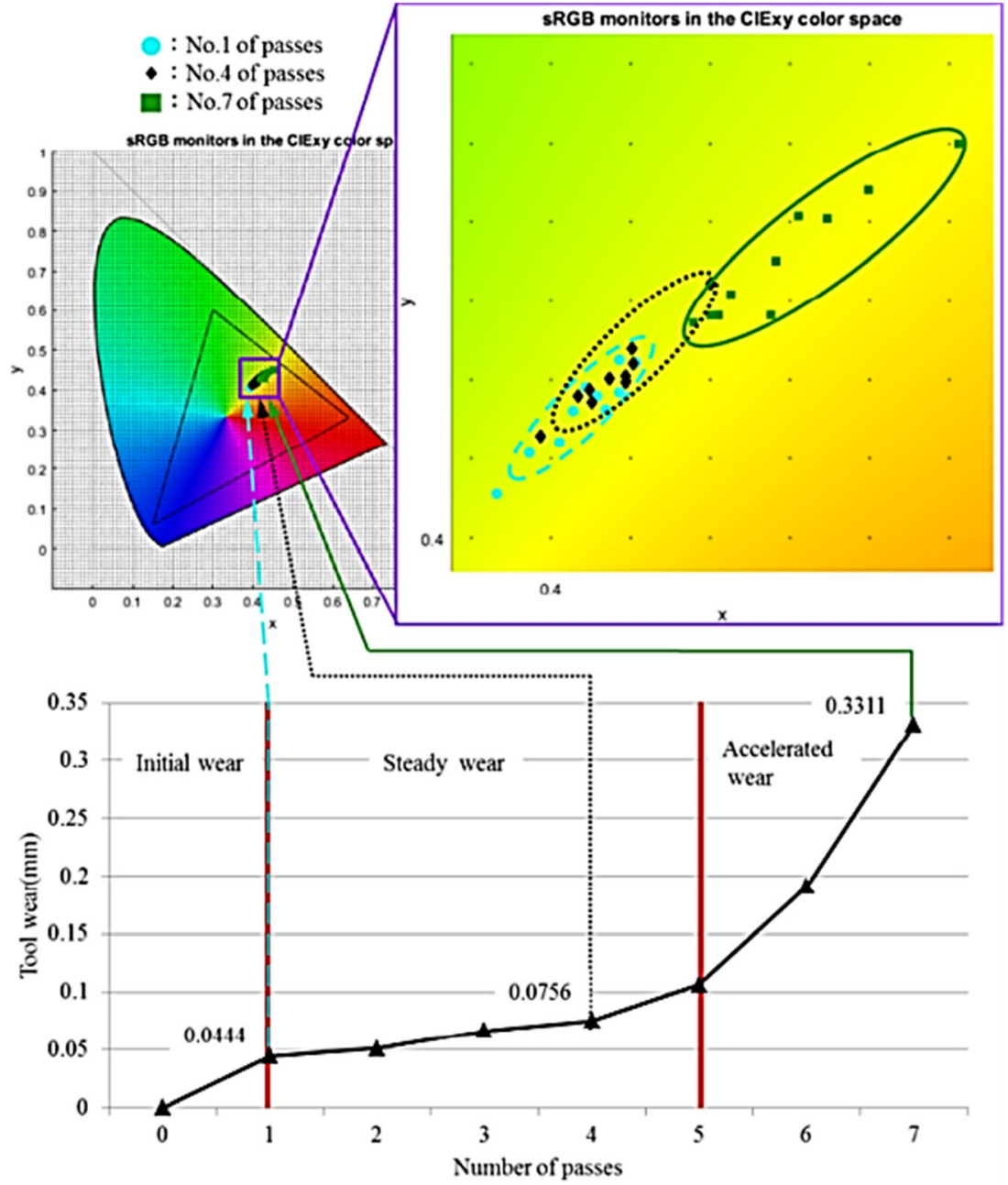

chromaticity coordinate points of chips expands as the wear loss increases.

Some elementary conclusions are summed up: The increase of tool wear will cause increasing chromaticity coordinate point area and vice versa.

\subsection{Test and verification results of prediction model of cutting tool wear}

The prediction was made using the back-propagation of the Artificial Neural Networks for this experiment. The basic architecture of the network consisted of an input layer, a hidden layer, and an output layer, which were connected with neurons, the experiment produces 21 material chips, and 2 pieces of each chip were picked for shooting, and each piece generated 42 chips as the parameters for test and verification. The shooting results are shown in Fig. 23 [24, 25].
1. The xy coordinate value of the CIExy chromaticity diagram is the same as that of the cutting experiment result, showing an inclination in gradual increase.

2 . In the experiment, the range of CIExy chromaticity coordinates is different from those in Figs. 20, 21, and 22. The larger the chromaticity coordinate range is, the larger range of prediction model of wear, and that's because this segment tests and verifies the wear, not the measurement. The experimental values are modeled due to the fact that it is more difficult for the range of fewer chromaticity points of the samplings to exhibit themselves [26].

This study inputs the parameters obtained during the test and verification experiments into the wear determination model to obtain the results, as shown in Tables 5 and 6 .

In this work, observing the results of the two groups shown in Figs. 24 and 25, we saw that when the amount of wear increases, the amount of error increases, and the maximum 
Fig. 23 Machining wear of model test and chromaticity coordinates
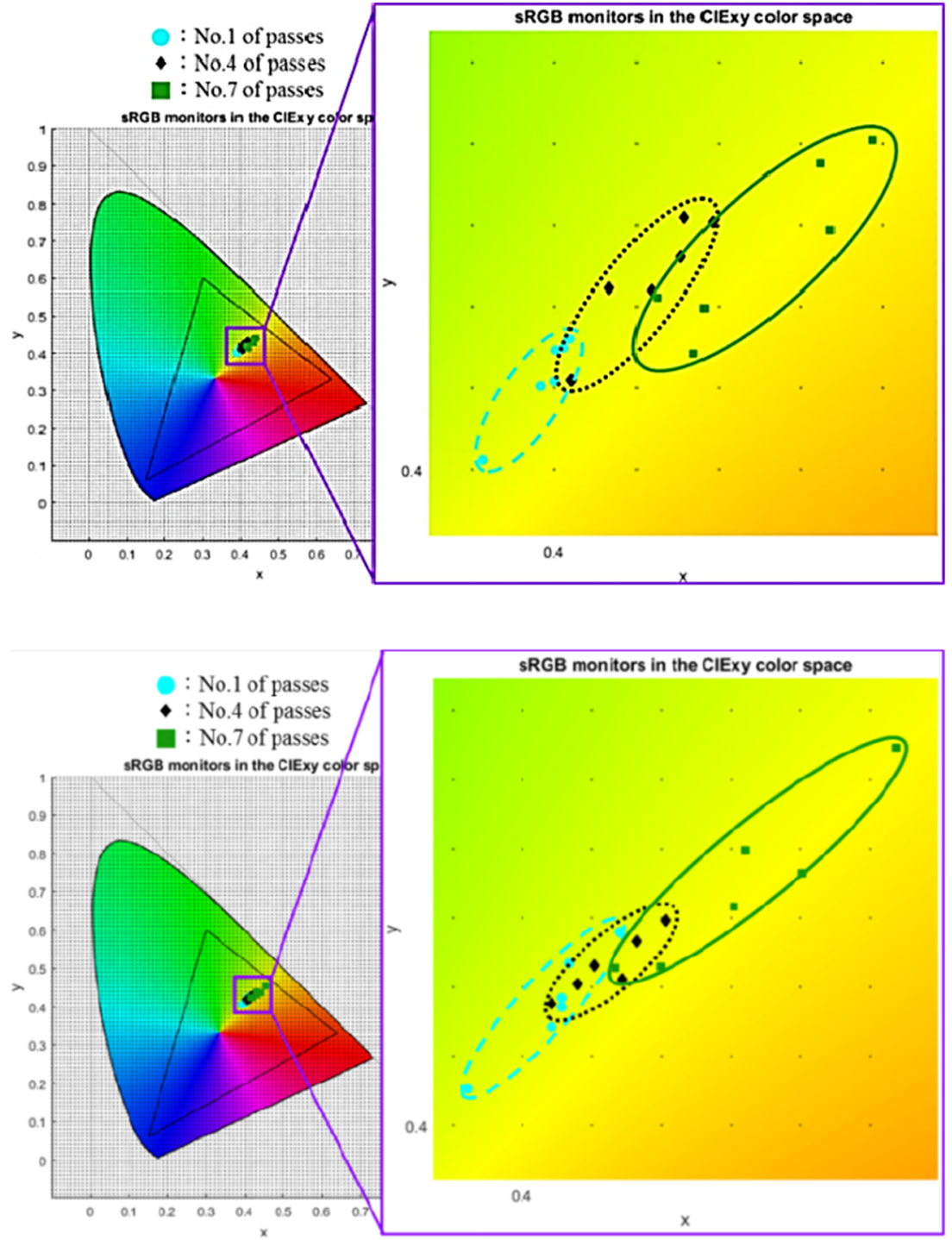

cutting before the tool wear reaches the upper limit of $0.3 \mathrm{~mm}$, with the maximum error range being $0.0120 \mathrm{~mm}$ and $0.0097 \mathrm{~mm}$, respectively. The calculated averaged error percentage is only $1.73 \%$ and $1.66 \%$, respectively, indicating that the tool wear prediction model established in this study is usable.

Table 5 Predicted model errors before the experimental wear reaching the upper limit

\begin{tabular}{ll}
\hline Maximum error value & $0.0050 \mathrm{~mm}$ \\
Minimum error value & $-0.0070 \mathrm{~mm}$ \\
Maximum error range & $0.00120 \mathrm{~mm}$ \\
Averaged error percentage & $1.73 \%$ \\
\hline
\end{tabular}

\section{Conclusion}

With the proposed this system, we only need to shoot chips and input cutting times to provide the industry with a simple and fast tool wear judgment method. The following conclusions can be listed through experiments:

Table 6 Predicted model errors before the experimental wear reaching the upper limit

\begin{tabular}{lc}
\hline Maximum value of error & $0.0040 \mathrm{~mm}$ \\
Minimum value of error & $-0.0057 \mathrm{~mm}$ \\
Maximum range of error & $0.0097 \mathrm{~mm}$ \\
Averaged percentage of error & $1.66 \%$ \\
\hline
\end{tabular}




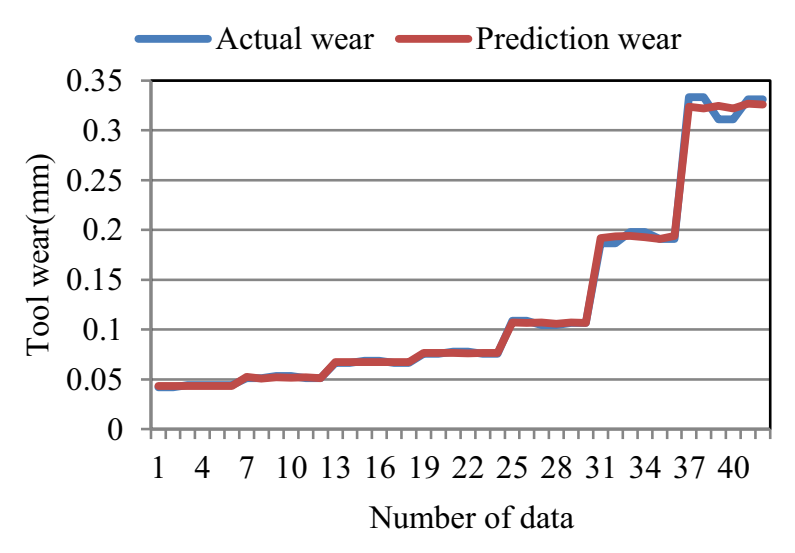

Fig. 24 Results of the tool wear prediction model test

1. If color correction is not carried out, it would be impossible to share with other photographic systems or to evaluate the color reproduction ability because this system is not standardized. The color correction model in this study can reduce the color difference value from $\Delta \mathrm{E} \_\mathrm{ab}^{\wedge *}=$ 18.6 to 2.94, with an improvement rate of $84.19 \%$.

2. According to Figs. 20, 21, and 22, the increase of tool wear also increases the $\mathrm{X}$ and $\mathrm{Y}$ values of CIExy chromaticity coordinates, and the chips would gradually change from light yellow to yellowish brown.

3. As shown in Fig. 24, most serious wear results in greater difference between the predicted and actual values. This is due to the fact that the shape of the edge of the tool is in an unstable status and changes rapidly at this time, plus the phenomenon caused by the accumulation of wear errors as the number of cuts increases. The increase of tool wear will cause increasing chromaticity coordinate point area and vice versa.

4. In this study, Taylor's tool life model and chip colors are used for analysis. After repeated testing and experimental analysis, the average error of repeatability is $4.5 \%$.

5. In prediction experiment and analysis, the back neural network is used for test, the maximum error ranges are $0.0012 \mathrm{~mm}$ and $0.0097 \mathrm{~mm}$, and the mean error percentages are only $1.73 \%$ and $1.66 \%$, meaning the cutting tool wear prediction model created in this study is usable.

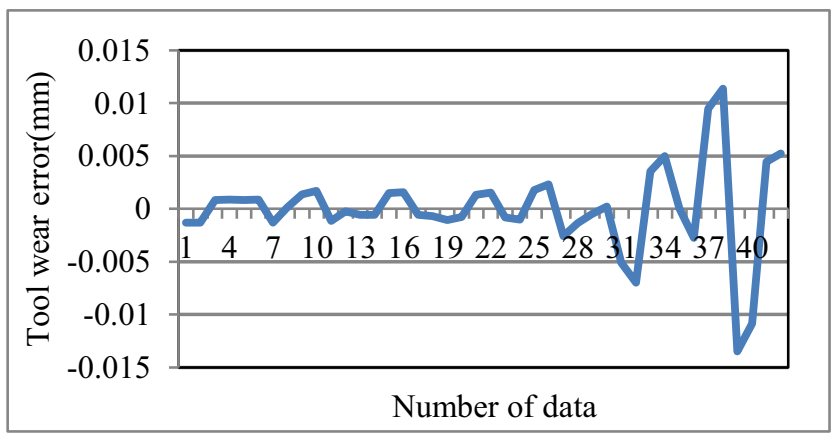

Fig. 25 Errors in tool wear prediction model test
Nomenclature $I_{0}=R_{0}, G_{0}, B_{0}$, Normalized RGB signal values; $I=R_{8-}$ bit, $\mathrm{G}_{8 \text {-bit }}, \mathrm{B}_{8 \text {-bit }}$, New 8-bit RGB signal values; $\gamma_{R} 、 \gamma_{G} 、 \gamma_{B}$, Value $\gamma$ of $\mathrm{RGB} ; \mathrm{X}, \mathrm{Y}, \mathrm{Z}$, Tristimulus values; $\mathrm{X}_{\mathrm{n}}, \mathrm{Y}_{\mathrm{n}}, \mathrm{Z}_{\mathrm{n}}$, Benchmark-white tristimulus value; L, Brightness; $C_{a b}{ }^{*}$, Chroma; $h_{a b}$, Hue; V , Cutting velocity (m/min); T , Tool life (min); fz , Feed per tooth (mm/tooth); tc , Chip thickness $(\mathrm{mm}) ; r_{\varepsilon}$, Nose radius $(\mathrm{mm}) ; \mathrm{a}_{\mathrm{p}}$, Cutting depth $(\mathrm{mm})$.

Open Access This article is licensed under a Creative Commons Attribution 4.0 International License, which permits use, sharing, adaptation, distribution and reproduction in any medium or format, as long as you give appropriate credit to the original author(s) and the source, provide a link to the Creative Commons licence, and indicate if changes were made. The images or other third party material in this article are included in the article's Creative Commons licence, unless indicated otherwise in a credit line to the material. If material is not included in the article's Creative Commons licence and your intended use is not permitted by statutory regulation or exceeds the permitted use, you will need to obtain permission directly from the copyright holder. To view a copy of this licence, visit http://creativecommons.org/licenses/by/4.0/.

\section{References}

1. Askeland DR, Fulay PP, Wright WJ (2011) The science and engineering of materials, SI edition sixth (6th) edition $(6 / \mathrm{E})$ TEXTBOOK

2. Debnath S, Reddy MM, Yi QS (2016) Influence of cutting fluid conditions and cutting parameters on surface roughness and tool wear in turning process using Taguchi method. Measurement 78: 111-119

3. Chinchanikar S, Choudhury SK (2015) Machining of hardened steel - experimental investigations, performance modeling and cooling techniques: a review. Int J Mach Tool Manuf 89:95-109

4. Diniz AE, Machado AR, Corrêa JG (2016) Tool wear mechanisms - in the machining of steels and stainless steels. Int $\mathrm{J}$ Adv Manuf Technol - Springer 87:3157-3168

5. Zhang S, Li JF, Deng JX, Li YS (2009) Investigation on diffusion wear during high-speed machining Ti-6Al-4V alloy with straight tungsten carbide tools. Int J Adv Manuf Technol 44(1-2):17-25

6. Huang TT, Chien WT (2003) Investigation on the predictive model for tool wear and surface roughness in milling SKD11 steel, Master Thesis, National Pingtung University of Science and Technology, Pingtung County, Chinese

7. Bar-Hen M, Etsion I (2017) Experimental study of the effect of coating thickness and substrate roughness on tool wear during turning. Tribol Int 110:341-347

8. Tsai CS, Chien WT (2002) The investigation on the predictive model for the wear of cutting tool and the optimized model for parameters based on cutting 17-4PH stainless steel, Master Thesis, National Pingtung University of Science and Technology, Pingtung County, Chinese

9. Korkut I, Boy M, Karacan I, Seker U (2007) Investigation of chipback temperature during machining depending on cutting parameters. Mater Des 28:2329-2335

10. Tekiner Z, Yesilyurt S (2004) Investigation of the cutting parameters depending on process sound during turning of AISI 304 austenitic stainless steel. Mater Des 25:507-513

11. Das SR, Panda A, Dhupal D (2018) Hard turning of AISI 4340 steel using coated carbide insert: surface roughness, tool wear, chip morphology and cost estimation. Mater Today 5:6560-6569

12. Zhang S, Guo YB (2009) An experimental and analytical analysis on chip morphology, phase transformation, oxidation, and their relationships in finish hard milling. Int J Mach Tools Manuf 49: 805-813 
13. Ning Y, Rahman M, Wong YS (2001) Investigation of chip formation in high speed end milling. J Mater Process Technol 113(1-3): 360-367

14. Cui X, Zhao B, Jiao F, Ming P (2017) Formation characteristics of the chip and damage equivalent stress of the cutting tool in highspeed intermittent cutting. Int J Adv Manuf Technol 91:2113-2123

15. Ortiz-de-Zarate G, Sela A, Saez-de-Buruaga M, Cuesta M, Madariaga A, Garay A, Arrazola PJ (2019) Methodology to establish a hybrid model for prediction of cutting forces and chip thickness in orthogonal cutting condition close to broaching. Int J Adv Manuf Technol 101:1357-1374

16. Ghani AK, Choudhury IA, Husni (2002) Study of tool life, surface roughness and vibration in machining nodular cast iron with ceramic tool. J Mater Process Technol 127:17-22

17. Kalpakjian S, Schmid SR (2014) Manufacturing engineering and technology. Pearson Publications, Singapore

18. Mia M, Królczyk G, Maruda R, Wojciechowski S (2019) Intelligent optimization of hard-turning parameters using evolutionary algorithms for smart manufacturing. Materials 12:879. https://doi.org/10.3390/ma12060879

19. Cui X, Zhao B, Jiao F, Zheng J (2016) Chip formation and its effects on cutting force, tool temperature, tool stress, and cutting edge wear in high- and ultra-high-speed milling. Int J Adv Manuf Technol 83:55-65
20. Hurst SO, Abad MD, Khanna M, Veldhuis SC (2012) Comparative wear behavior studies of coated inserts during milling of $\mathrm{NiCrMoV}$ steel. Tribol Int 53:115-123

21. Sikdar SK, Chen MY (2002) Relationship between tool flank wear area and component forces in single point turning. J Mater Process Technol 128:210-215

22. Jii W. Industry Company, Ltd., Material technical report, Taiwan

23. Syu MJ (2001) Advanced cutting technology. Fuhan Publishing book, Tainan City

24. Jantunen E (2002) A solution for tool wear diagnosis, in: proceedings. Int J Mach Tools Manuf 42(997-1010) 1999:95-104

25. Rao KV, Murthy BSN, Rao NM (2014) Prediction of cutting tool wear, surface roughness and vibration of work piece in boring of AISI 316 steel with artificial neural network. Measurement 51:6370

26. Stavropoulos P, Papacharalampopoulos A, Vasiliadis E, Chryssolouris G (2016) Tool wear predictability estimation in milling based on multi-sensorial data. Int J Adv Manuf Technol 82(14):509-521

Publisher's note Springer Nature remains neutral with regard to jurisdictional claims in published maps and institutional affiliations. 